\title{
PLANNING FOR STOP SPACING UNDER THE SAN FRANCISCO MUNICIPAL TRANSPORTATION AGENCY BUS STOP CONSOLIDATION PROPOSAL
}

\author{
A Thesis \\ presented to \\ the Faculty of California Polytechnic State University, \\ San Luis Obispo
}

\author{
In Partial Fulfillment \\ of the Requirements for the Degree \\ Master of Science in Engineering/Master of City and Regional Planning \\ (Transportation Planning Specialization)
}

by

Erin Marie Cooper

May 2010 
(c) 2010

Erin Marie Cooper

ALL RIGHTS RESERVED 


\section{COMMITTEE MEMBERSHIP}

TITLE: Planning for Stop Spacing Under the San Francisco Municipal

Transportation Agency Bus Stop Consolidation Proposal

AUTHOR: Erin Marie Cooper

DATE SUBMITTED: May 2010

COMMITTEE CHAIR: ................................ Cornelius Nuworsoo, Ph. D., AICP COMMITTEE MEMBER:.................................................. Anurag Pande, Ph.D.

COMMITTEE MEMBER:..................................................... Eugene Jud, P.E. 


\section{ABSTRACT \\ Planning for Stop Spacing Under the San Francisco Municipal Transportation Agency Bus Stop Consolidation Proposal}

\section{Erin Marie Cooper}

The purpose of this report was to analyze the elements of a bus stop consolidation program for the San Francisco Municipal Transportation Agency (SFMTA). This research shows that increasing stop spacing distances increases walking distances, but in places with high transit and stop density, most access distances will not be beyond a five to ten minute walk. In general, European cities with high transit mode shares recommend stops every 1300 feet. American guidelines recommend stops between approximately 800 to 1300 feet. According to the literature review, fewer stops can lead to a more reliable service. Time savings on the route also translate into significant cost savings for the agency.

This paper presents a methodology for creating stop elimination proposals based on factors such as ridership, transfer points, and existing bus shelters or infrastructure. Public input can help to determine which bus stops are key locations. This methodology was used to propose stop consolidation for one bus route in San Francisco: Route 1 California Inbound. The route was then evaluated based on information from the literature review. The yearly savings can be as much as $\$ 340,000$ to $\$ 930,000$ per route.

Keywords: Bus Stop Spacing Standards, Reliability, Stop Consolidation, Transit, Operations 


\section{ACKNOWLEDGMENTS}

I would like to thank the transportation planners at the SFMTA who provided much of the initial data and project development.

I would also like to thank my committee chair and members who helped to further develop the initial ideas of this thesis. 


\section{TABLE OF CONTENTS}

List of Figures

viii

List of Tables

viii

CHAPTER 1: INTRODUCTION 1

CHAPTER 2: BACKGROUND OF SAN FRANCISCO AND STOP SPACING PROJECTS

2.1 EXISTING CONDITIONS

HISTORY OF STOP PLACEMENT IN SAN FRANCISCO

CONSIDERATIONS IN DEVELOPING EXISTING STANDARDS

RECENT EFFORTS

2.2 IMPACT OF STOP SPACING ON SERVICE PERFORMANCE

TRAVEL TIME AND RIDERSHIP

RELIABILITY AND WAITING TIME

POTENTIAL FOR COST SAVINGS

CONCLUSION

CHAPTER 3: BEST PRACTICES RESEARCH

3.1 FACTORS IN PLACING BUS STOPS

CLOSE STOPS VERSUS STOPS FARTHER APART

OPERATIONS-FOCUSED FACTORS

PEDESTRIAN-FOCUSED FACTORS

FARSIDE AND NEARSIDE STOPS

ADDITIONAL CONSIDERATIONS

3.2 BUS STOP SPACING STANDARDS IN THE US

3.3 INTERNATIONAL BUS STOP SPACING STANDARDS

3.4 ACCESS TO BUS STOPS

3.5 DISABLED PERSONS AND ELDERLY

3.6 STANDARD ADOPTION

3.7 PUBLIC PARTICIPATION

CHAPTER 4: CONSOLIDATION PROCESS

4.1 General ISSUES

ACCESSIBILITY

PROXIMITY TO MAJOR ACTIVITY CENTERS

TRANSFERS

EXISTING BUS STOPS AND SHELTERS

HIGH RIDERSHIP STOPS

4.2 METHOdOLOGY 
ANALYSIS OF NETWORK WALKING DISTANCES

ANALYSIS PROCESS FOR ONE BUS ROUTE

EVALUATION OF NEW ROUTE PROPOSAL 39

4.3 CASE APPLICATION $\quad 40$

ANALYSIS OF NETWORK WALKING DISTANCES

ANALYSIS PROCESS FOR ONE BUS ROUTE: ROUTE 1 CALIFORNIA INBOUND

ALTERNATIVE APPROACHES

EVALUATION OF NEW ROUTE PROPOSAL

CHAPTER 5: PUBLIC OUTREACH AND IMPLEMENTATION

5.1 Public OUTREACH 63

5.2 IMPLEMENTATION $\quad 64$

REVISED SCHEDULES $\quad 64$

ELIMINATION OF BUS SHELTERS

NOTIFICATION OF STOP CHANGES $\quad 65$

MARKING STOP REMOVAL $\quad 65$

EVALUATION OF TEST ROUTE $\quad 66$

CHAPTER 6: CONCLUSION $\quad 67$

\begin{tabular}{ll} 
REFERENCES & 70 \\
\hline
\end{tabular}

APPENDIX 1: ROUTE 1 CALIFORNIA OUTBOUND - STOPS WITH STANDARD DEVIATIONS GREATER THAN ONE

APPENDIX 2: ROUTE 1 CALIFORNIA OUTBOUND - LIST OF StOPS TO KeEP 


\section{LIST OF FIGURES}

FIGURE 2-1. DIAGRAM OF VARIABLE RELATIONSHIPS 15

FIGURE 2-2. BUS FUEL CONSUMPTION BY STOPS PER MILE 17

FIGURE 2-3. TRUCK FUEL CONSUMPTION VERSUS VELOCITY 18

FIGURE 2-4. TRUCK OIL CONSUMPTION

FIGURE 3-1. STOP SPACING TRADE-OFF 22

FIGURE 4-1. 1/4 MILE FROM STOP LOCATIONS

FIGURE 4-2. 1/8 MILE FROM STOP LOCATIONS

FIGURE 4-3. INITIAL DATA ON ROUTE 1 - CALIFORNIA

FIGURE 4-4. THREE SEGMENTS FOR ANALYSIS

FIGURE 4-5. ROUTE DATA DIVIDED INTO SEGMENTS 46

FIGURE 4-6. SEGMENT 1: VALUES AND STANDARDIZED SCORES

FIGURE 4-7. SEGMENT 2: VALUES AND STANDARDIZED SCORES

FIGURE 4-8. SEGMENT 3: VALUES AND STANDARDIZED SCORES

FIGURE 4-9. HIGH RIDERSHIP POINTS MARKED

FIGURE 4-10. KEY TRANSFER POINTS MARKED

FIGURE 4-11. ALTERNATIVE TRANSFER POINTS MARKED

FIGURE 4-12. EXISTING SHELTERS MARKED

FIGURE 4-13. LIST OF STOPS TO KEEP

FIGURE 4-14. FINAL LIST OF STOPS

FIGURE 4-15. ROUTE 1 CALIFORNIA: 1/8 AND 1/4 MILE BUFFERS

FIGURE 4-16. MODIFIED ROUTE 1 CALIFORNIA: 1/8 AND 1/4 MILE BUFFERS

FIGURE 4-17. SUMMARY OF COST ESTIMATION PROCESS 60

\section{LIST OF TABLES}

TABLE 2-1. EXISTING STOP SPACING STANDARDS FOR SAN FRANCISCO 6

TABLE 2-2. PROPOSED STOP SPACING STANDARDS FOR SAN FRANCISCO 7

TABLE 2-3. ILLUSTRATION OF 25\% INCREASE IN TERMS OF SPEED, DISTANCE, AND TIME

TABLE 2-4. ESTIMATED TIME SAVINGS WITH SELECTED IMPROVEMENTS 13

TABLE 3-1. TCRP STOP PLACEMENT CRITERIA AND EXPLANATION 23

TABLE 3-2. CONSIDERATIONS FOR SITING STOPS FAR-SIDE, NEAR-SIDE, OR MID-BLOCK

TABLE 3-3. TYPICAL STOP SPACING

TABLE 3-4. STANDARDS FOR VARIOUS CITIES

TABLE 3-5. INTERNATIONAL STOP SPACING EXAMPLES

TABLE 3-6. CTA STOP COVERAGE

TABLE 4-1. DWELL TIME REDUCTION ESTIMATES

TABLE 4-2. DWELL TIME REDUCTION ESTIMATES

TABLE 4-3. ESTIMATED SAVINGS IN OPERATING AND SOCIETAL COSTS

TABLE 4-4. AVERAGE SPEED INCREASE ESTIMATE

TABLE 4-5. REDUCTION IN COSTS BASED ON AVERAGE SPEED INCREASE

TABLE 4-6. FUEL CONSUMPTION BASED ON STOPS PER MILE 62 


\section{CHAPTER 1: INTRODUCTION}

The San Francisco Municipal Transportation Agency (SFMTA) is currently working on the Transit Effectiveness Project. This project aims to enhance the reliability, speed, and frequency of the public transit service and focus resources in areas where they are most needed (SFMTA 2009b). The Agency collected ridership data on bus routes and light rail lines through automatic passenger counters (APCs) and used the data to make recommendations on changes to bus routes and rail lines. In addition to arranging resources to better serve the public, SFMTA has proposed changing the stop spacing standards in the existing guidelines and consolidating bus stops as one measure to increase the reliability and speed of bus routes. This report looks at one high ridership route in the City which is a candidate for stop consolidation.

Cities around the country develop stop spacing guidelines to address issues such as increasing bus reliability and reducing travel times along routes. Potential benefits from optimal stop spacing stem from known concepts in transit development. One factor in reducing route travel time is reducing the dwell time at each stop to allow for passenger boardings and alightings. Another factor is the frequency of bus stops. If a bus is stopping less frequently, there will be fewer dwell times and less time spent accelerating and decelerating leading to reduced fuel consumption. Concentrating passengers at fewer stops makes boarding faster per passenger over the course of the route as well as passenger loads more predictable. Greater predictability can lead to greater accuracy in scheduling 
and ideally, greater reliability of the service. Reliability and schedule adherence are both factors which make the system easy for transit riders to use. To determine whether or not a stop consolidation program would benefit the rapid routes in San Francisco, this paper looks at research on each of these issues.

Any savings achieved due to travel time reduction or reduced maintenance from less acceleration or deceleration can be reinvested in the system in many forms. Savings can be spent on enhancing bus stop amenities at the locations which can provide better customer information as well as better stop design to allow for faster, easier, and safer boarding. Savings due to decreased travel time can be translated into increased frequency along the route. Having adequate bus frequency to serve the passenger demand along a route is linked to reliability. Any buses which may not be needed due to decreased travel times can be used as back-up buses to allow the agency to respond more quickly when a bus breaks down in service.

The process of creating stop spacing guidelines may be controversial because many American transit systems have an abundance of stops, especially compared to European systems. Re-evaluating stop spacing often involves eliminating stops which may have been specifically requested in the past. Intuitively, reducing the number of stops means that walking distances to stops for some people will be increased, therefore this paper will investigate what previous research on optimizing stop spacing shows about effects on passenger access.

This paper shows that there are several factors to address when proposing bus consolidation possibilities for an agency. Many studies look at optimal bus 
stop spacing through modeling, access time, travel times for customers, geographical access to bus stops, and walking distances. Stop spacing is considered a function of walking distance, population served, the percent of transit riders in the area, and major activity centers or transfer points. The specific siting of bus stop locations can be decided through data about the stops and public input. There are also agency constraints which include the process and cost of changing, removing, or adding bus stops. This thesis further discusses these factors which are then used to develop criteria for placing bus stops.

After identifying these factors, this study develops a methodology for choosing stops for elimination assuming that SFMTA does not want to unnecessarily move stops when there is already an abundance of stops, and in many cases bus stop infrastructure. The factors for siting stops are ranked and applied to the existing data on stop spacing and infrastructure. Key locations which consist of those with very high ridership activity or allow for transfers are marked first as important stops to keep. Alternative transfer locations and stops with existing shelters are marked as locations which should be kept if possible. The rest of the stops are placed based on this data and the stop spacing guidelines. A before-and-after analysis of the route was done using GIS and benefit values from the literature review. The GIS maps show the change in coverage area for the route as existing and the route as proposed. The route analysis shows the estimated time and cost savings if these changes are implemented. 
Chapter Two of the report looks into the history of stop placement and stop spacing standards in San Francisco. It also discusses recent efforts leading to this project and benefits and cost-savings associated with increasing stop spacing. Chapter Three has best practice research for stop spacing standards in both the US and internationally. This section addresses the question of how the stop spacing standards will reduce delay to onboard customers versus the potential increase in walking distances to bus stops. Chapter Four shows the methodology used as well as an analysis of the results of stop elimination. Chapter Five focuses on implementation of the stop consolidations and community outreach. 


\section{CHAPTER 2: BACKGROUND OF SAN FRANCISCO AND STOP SPACING PROJECTS}

This chapter will discuss existing conditions regarding stop spacing in San Francisco. It also presents research about the impacts of stop spacing on bus service performance.

\subsection{Existing Conditions}

\section{History of stop placement in San Francisco}

There is limited history on how the original Municipal Railway (Muni) placed stops throughout the city. According to Peter Straus (personal communication, September 3, 2009), the former manager of service planning, streetcars on Market Street stopped at each block, and achieved faster service than today due to lack of traffic. As automobile use became more widespread, more pole stops were put in place instead of bus zones to allow for more parking spaces on streets. Additional street congestion in the city resulted in greater delay for transit vehicles. By the 1970s, the 'Schedules' division of Muni was in control of placing bus stops. Requests were made for bus stops along routes, and the requests were generally met. The Service Planning division eventually took over placing stops, in part to limit the number of stops being placed on routes based on reports showing that additional stops increase the travel time of the vehicles. Through the Short Range Transit Plan (SFMR, 1979), standards for stop spacing were 
recommended, recognizing that streets with steeper slopes should have separate guidelines.

These standards became the guidelines that are used today for assessing stop placement (Table 2-1). These standards were used when developing new routes or reviewing stop requests, however, the entire system has not been systematically reviewed to fit the existing standards.

Table 2-1. Existing stop spacing standards for San Francisco

\begin{tabular}{|l|l|}
\hline Slope grade & Distance range \\
\hline Grades $<=10 \%$ & $800-1000$ feet \\
\hline Grades $10 \%$ to $15 \%$ & $500-600$ feet \\
\hline Grades $>15 \%$ & $300-400$ feet \\
\hline
\end{tabular}

Source: SFMTA 2009a

\section{Considerations in developing existing standards}

The San Francisco Municipal Railway 5-year Plan for 1979 to 1984 discusses the original intent in developing stop spacing guidelines. It states that closely spaced stops reduce walking distance but increase "jerkiness, accident rates, and travel times" (SFMR, 1979:22). The purpose in creating standards is to "maximize safety, comfort, speed, and capacity while ... minimizing walking" (SFMR, 1979:22). Special attention is paid to walking distances in hilly areas versus flat areas, transfer points, and major destinations such as hospitals or schools.

The benefits of current stop spacing standards are that almost all of the City is within a five minute walk of at least one bus stop, as shown later in Figure 4-1 and 4-2. There are many stops in steep areas providing a high degree of 
accessibility, which is a particular concern for people with limited mobility. Buses stop at almost all possible transfer points and major destinations. New proposals should attempt to retain these qualities even when eliminating bus stops.

\section{Recent efforts}

As a result of data collected from the Automatic Passenger Counters (APCs) on Muni buses, statistics on the existing conditions of the transit services are available. This data showed that the distances between 70 percent of the stops are below the guideline. Seventeen percent meet the guideline, and 13 percent exceed the guideline (SFMTA, 2009a). The new guidelines were developed to match the block structure in different parts of the city. The proposed policy (Table 2-2) will place stops between two and four blocks apart which is roughly between 900 and 1400 feet.

Table 2-2. Proposed stop spacing standards for San Francisco

\begin{tabular}{|l|l|}
\hline Slope grade & Distance range \\
\hline Grades $<=10 \%$ & $900-1400$ feet \\
\hline Grades $>10 \%$ & As close as 500 feet \\
\hline
\end{tabular}

Source: SFMTA 2009a

These standards are considered guidelines and can change based on specific locations which may require more or less service. The data also shows (SFMTA, 2009a) that approximately 20 percent of the travel time on the high ridership routes is dwell time. Additionally, it shows that as the number of boardings per stop increases the dwell time per boarding decreases. Similar to the lag that is 
experienced due to reaction time at a traffic signal, there appears to be a lag in boarding the first few customers. Reducing the number of initial customers to board at any location should reduce the overall dwell time on a route.

Two proposals have been made for stop changes on many of the existing high ridership routes. These proposals are generally based on distances between stops, grades between stops, and ridership data for the stops. The existing stop consolidation proposals were developed before the new stop spacing standards (shown in Table 2-2). The proposals presented in Chapter 4 take the newly developed stop spacing standards into account.

\subsection{Impact of Stop Spacing on Service Performance}

Stop spacing standards are put in place to create faster bus trips while also providing an accessible service. Many cities such as Portland, Chicago, and Seattle, as well as the Transit Cooperative Research Program (TCRP), recognize that more frequent stops can mean shorter walking distances to stop locations, but reduces the speed of the buses and makes them less attractive for customers. This section presents selected literature on the effects of stop spacing on travel time, wait time, and cost savings.

\section{Travel time and ridership}

In Chicago (CTA, 2003), express routes were developed as an alternative to the local routes. This does not reflect exactly what is being proposed for San Francisco but illustrates the impact of reducing the number of stops on travel 
speed and ridership. Whereas local routes might have stops as close as $1 / 8$ of a mile apart, the express routes have stops between $1 / 2$ a mile and 1 mile apart. In developing the express routes, this policy translated to an elimination of 75 percent of the stops on the route. The resulting average travel speeds are 25 percent higher than on the local line, and the resulting increase in ridership along the corridor was 18 percent (CTA, 2003). Table 2-3 illustrates what this travel speed increase represents. If the original average speed was $10 \mathrm{mph}$, a 25 percent increase in speed would increase this speed to $12.5 \mathrm{mph}$. This means that if a bus originally could travel 5 miles in 30 minutes, the bus could now travel an additional 1.25 miles in the same amount of time. Alternatively, the higher speed means the bus could travel the same 5 miles in 24 minutes instead of 30 minutes. This equates to a 20 percent time savings on one direction of the route.

Table 2-3. Illustration of $25 \%$ increase in terms of speed, distance, and time

\begin{tabular}{|l|c|c|}
\hline & Normal & $\begin{array}{c}\mathbf{2 5 \%} \text { increase } \\
\text { in speed }\end{array}$ \\
\hline Speed & $10 \mathrm{mph}$ & $12.5 \mathrm{mph}$ \\
\hline Distance & $5 \mathrm{miles}$ & $6.25 \mathrm{miles}$ \\
\hline Route Time & $30 \mathrm{~min}$ & $24 \mathrm{~min}$ \\
\hline
\end{tabular}

A study on the bus system in Curitiba, Brazil also compares local routes and express routes. The local routes in Curitiba average $12 \mathrm{mph}$ while the express routes average $19 \mathrm{mph}$ (Curitiba, 2003). It also estimates that 15 minutes are saved on each one-way segment of an express route trip, which means savings of 30 minutes for a round trip. Part of the time savings is attributable not only to fewer bus stops, but also to reduced boarding time or dwell time. The 
study shows that even at sites where there are large numbers of boardings, dwell time can be as short as 15 and 20 seconds. Wide bus doors, multiple bus doors, level access, prepayment and passes all contribute to faster boarding. Curitiba's bus ridership has increased roughly 4.5 percent a year between 1971 and 2000, and transit falls between 70 and 75 percent of the mode share for journeys to work. Roughly 30 percent of San Francisco's journeys to work are by transit (American Community Survey, 2008).

Another recent study looks at TriMet's effort to improve bus reliability and travel time in Portland, Oregon (El-Geneidy, Kimpel, and Stratham, 2005). The project included bus stop consolidation, signal priority, roadway improvements, stop amenities, parking restrictions, and further compliance with the Americans With Disabilities Act (ADA) (EI-Geneidy et al., 2005). The agency's theory behind stop consolidation is that having fewer stops will concentrate passengers thereby reducing travel times and increasing reliability. El-Geneidy et al. (2005) studied the effect of Tri-Met's bus stop consolidation project on passenger activity and travel time. Segments of a bus route fell into two categories: treated segments, those which had stop consolidation, and control segments, those that remained the same. Running time on each of these segments declined by between two and nine percent. The report shows that overall, the theory of concentrating passengers did decrease the overall running time, and did not reduce the number of passengers. The report also states that running times could be further reduced from what this study has shown because schedules, which were adjusted to 
accommodate the stop consolidation, may not have been adjusted enough. This report estimates that each stop elimination reduces running time by 42.2 seconds.

The same study did not find, however, that stop consolidation increased reliability, though this could be due to inadequate scheduling. Previous studies have shown that boarding or dwell time would have an effect on the reliability of the service. Vuchic ( in Turnquist, 1981) linked a reduction in boarding time to a reduction in bus bunching. Bus bunching is related to the demand for a route, frequency of service, and variability in travel time. If stop consolidation makes passenger activity more predictable and reduces boarding time, it should make route travel times more predictable as well. Kittleson \& Associates (2006) list factors such as the number of stops made to serve passengers and the number of left turns on public streets as significant variables affecting route travel time.

Another stop study focusing on Massachusetts Bay Transportation Authority bus routes used a modeling approach to find the optimal bus stop spacing (Furth and Rahbee, 2000). The current average stop spacing is $200 \mathrm{~m}$ ( $\sim 660$ feet). The model found the optimal stop spacing to be $400 \mathrm{~m}$ ( 1310 feet or roughly $1 / 4$ of a mile) based on the analysis of variables such as walking time, riding time, and operating time. The time value of money was given for each of these as $\$ 10 /$ hour, $\$ 4 /$ hour, and $\$ 80 /$ hour. The model also uses estimated values for bus operating speeds, $12 \mathrm{mph}$, bus acceleration and deceleration speeds, 3 $\mathrm{mph} / \mathrm{s}$, and dwell time, 9 seconds. The model developed a total societal cost per hour to compare the various alternatives and found that the optimal versus the existing stop spacing saved $\$ 132$ per hour. It is important to note that walking time 
was taken into account, and still longer stop spacing was recommended.

Passenger activity and accessibility of stops is not necessarily affected as much as we might imagine. A study of New York transit stops which were increased from an average of $160 \mathrm{~m}$ ( $\sim 20$ feet) to $230 \mathrm{~m}$ ( 750 feet), or by 44 percent, reduced accessibility by only 12 percent (EI-Geneidy et al., 2005).

According to Murray and Wu (2003), it is generally accepted that reducing the number of stops on a route will reduce access but decrease travel times. There will be a point where having an excessive travel time will reduce demand on the route. If an agency's goal is to increase the transit mode share, decreasing travel time is an important component (Waterson, Rajbhandari, and Hounsell, 2003; Newman and Kenworthy, 1999 in Murray and Woo, 2003). Murray and Wu (2003) studied stop optimization for Columbus, Ohio by analyzing stop spacing in terms of spatial access to stops and looking at the passenger population around each stop. This study showed that access decreased by approximately three percent when stop spacing was increased by 33 percent from roughly 300 to 400 meters.

The Massachusetts Executive Office of Transportation (EOT) is also planning to improve bus routes in the local area. Currently, about half of the stops are between 300 and 600 feet apart. The plan includes stop consolidation, bus stop improvements to ease boarding and improve safety, and bus priority signalization. The agency estimates (shown in Table 2-4) that on one of the lines, they will see between a six and twelve percent time savings with bus stop consolidation. If curb extensions are added, the savings increase to between nine 
and fifteen percent. If signal priority is included the time savings can be between 11 and 18 percent in each direction on a route.

The agency also estimates consolidating bus stops and adding curb extensions will increase the number of parking spaces available. Flag stops do not require curbside space like bus zones or curb extensions. However, if the agency would like to increase safety at stop locations and create stops that are accessible for all segments of society, bus zones and curb extensions may be needed in many locations. If these treatments are added at every stop, the number of parking spaces along the route will be reduced. If these treatments are added at specific locations along the route, the number of parking spaces along a route could increase (EOT, 2008).

Table 2-4. Estimated time savings with selected improvements

\begin{tabular}{|c|c|c|c|c|}
\hline $\begin{array}{c}\text { Bustrip } \\
\text { direction }\end{array}$ & $\begin{array}{c}\text { Existing } \\
\text { trip time }\end{array}$ & $\begin{array}{c}\text { With } \\
\text { Consolidation }\end{array}$ & $\begin{array}{c}\text { With } \\
\text { consolidation \& } \\
\text { curb extensions }\end{array}$ & $\begin{array}{c}\text { With consolidation, } \\
\text { aurb extensionsand } \\
\text { signal optimization }\end{array}$ \\
\hline Inbound & $35 \mathrm{~min}$. & $\begin{array}{c}2-3 \mathrm{~min} . \\
(6-9 \%)\end{array}$ & $\begin{array}{c}3-4 \mathrm{~min} . \\
(9-11 \%)\end{array}$ & $\begin{array}{c}4-5 \mathrm{~min} . \\
(11-14 \%)\end{array}$ \\
\hline Outbound & $34 \mathrm{~min}$. & $\begin{array}{c}3-4 \mathrm{~min} . \\
(9-12 \%)\end{array}$ & $\begin{array}{c}4-5 \mathrm{~min} . \\
(12-15 \%)\end{array}$ & $\begin{array}{c}5-6 \mathrm{~min} . \\
(15-18 \%)\end{array}$ \\
\hline
\end{tabular}

Source: EOT, 2008

Bus priority measures need to be carefully implemented. Waterson, Rajbhandari and Hounsell (2003) found that strong bus priority measures may not be as effective as moderate bus priority measures. The report shows that congestion points along a route, such as bus stations or particularly congested areas, limit the effectiveness of bus priority measures. These areas determine the throughput capacity of buses over the course of the route. 


\section{Reliability and waiting time}

Reliability is often an operating performance indicator that agencies wish to improve when considering bus stop consolidation. Bowman and Turnquist (1981) recognize that frequency of service is not as important to the customer as having a reliable schedule. Greater reliability means that if customers know the bus schedule, they will not have to wait as long at the bus stop. One study looking at bus stops in Singapore (Mohring, Schroeter, and Wiboonchutikula, 1987) shows that the value of waiting time versus the value of time on the bus is related to income and "the value of waiting time is about two to three times that of time in transit" (Mohring et al., 1987:41). Oort and Nes (2003) show that waiting time is valued twice as much as transit time. These studies, and many transit agencies, realize that unreliable transit, which causes seemingly excessive wait times, will decrease ridership.

From the point of view of the operator, attracting and serving the needs of current customers can be achieved by establishing a reliable system. There are three main measures of reliability according to Liu and Sinha (2007): headway reliability, run-time reliability, and passenger wait time reliability. The most important factor in variability for the run-time, in this study, was the length of the route. Kittleson \& Associates (2006) showed that route length was an important factor in predicting travel times along a route. However, having a non-uniform distribution of dwell times was also shown to increase the variability in headways, 
and reducing passenger boarding times was shown to increase reliability as well (Liu and Sinha, 2007).

Data collected from Automatic Passenger Counters (APCs) in San Francisco showed that the average time for passenger boarding decreases with the number of passengers boarding at each stop. The TriMet study (El-Geneidy et al., 2005) also showed that bus stop consolidation made a more predictable number of passengers at each stop. This shows that stop consolidation will likely impact the overall dwell time and variability of headways over the route making the buses more reliable. Figure 2-1 depicts the relationship of the variables related to stop spacing and transit operations.

Figure 2-1. Diagram of Variable Relationships

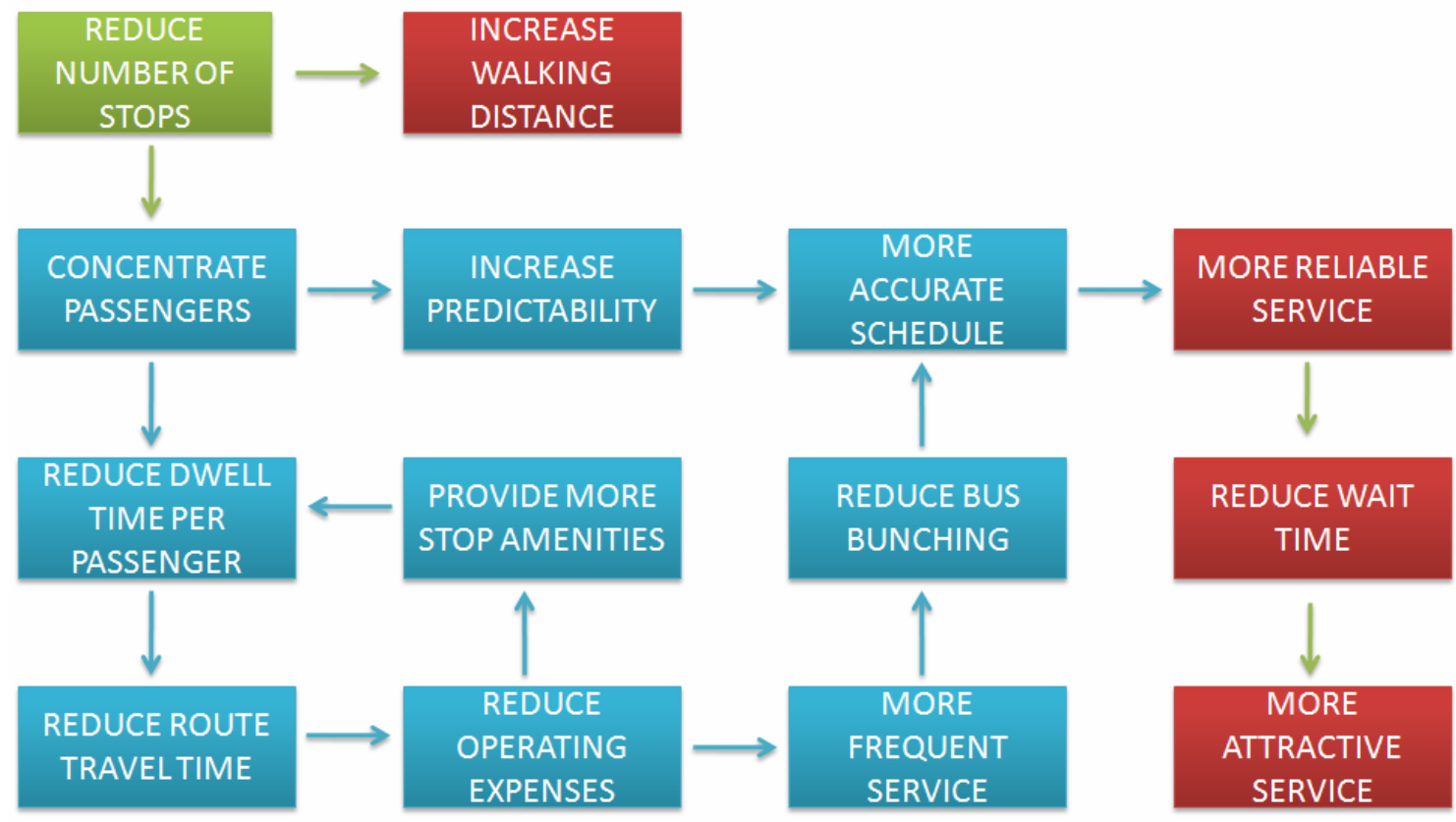

Potential for cost savings 
Three main areas have been identified for cost saving potential in the stop consolidation project. First, there are savings due to reduced operating time if the stop consolidation reduces the run time of the route. SFMTA has developed a model for estimating time savings produced through reducing the number of hours of operation. Second, there are potential savings in bus maintenance and fuel consumption associated with reducing the amount of acceleration and deceleration of the buses. Third, because the current operating speeds are quite slow, increasing the average speed reduces fuel and oil consumption.

Generally, the Federal Highway Administration (2009) recognizes that aggressive driving increases the fuel consumption of a vehicle. Aggressive driving is defined as accelerating and decelerating repeatedly. Though bus drivers are not necessarily aggressive, they must accelerate and decelerate for each bus stop. Vuchic (2007:139) states that "acceleration consumes most of the energy used in travel." Vuchic (2007) also provides a graph showing the increased consumption of fuel with respect to the number of bus stops per mile (Figure 2-2). This data can be used to quantify fuel savings for reducing the number of stops on a route. 


\section{Figure 2-2. Bus fuel consumption by stops per mile}

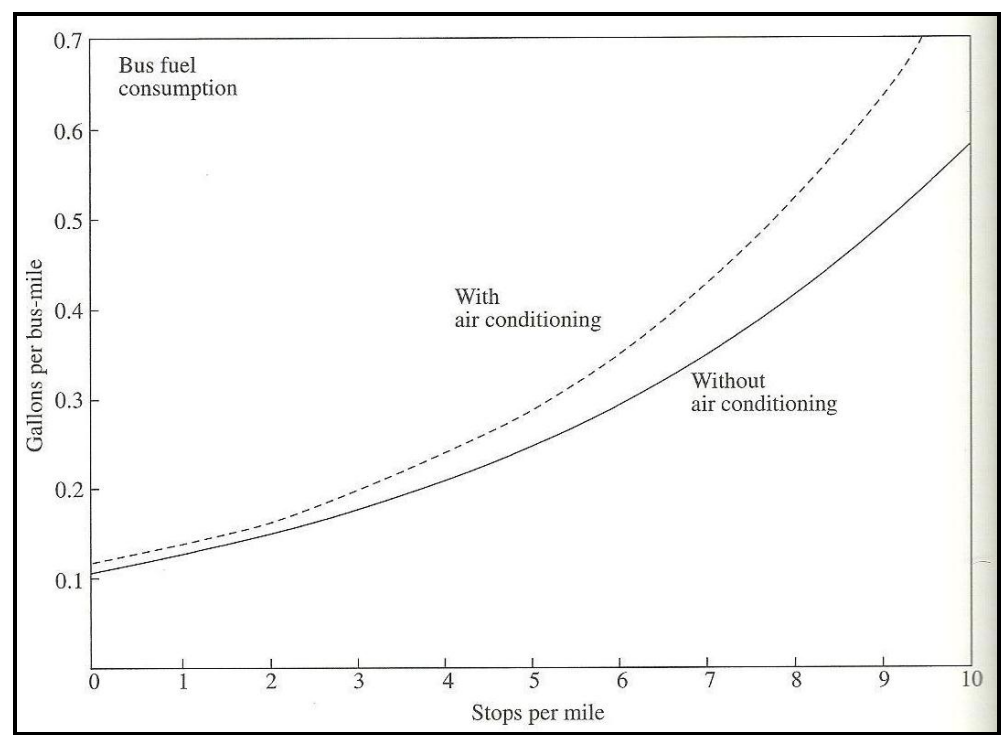

Source: Raus, 1981 in Vuchic 2007

There is also data showing that vehicles get their best gas mileage at midrange speeds, as opposed to driving very slowly or very fast (US DOE, 2009). Research also shows that for cars and trucks, fuel consumption, oil consumption, and vehicle depreciation are based on the constant velocity of the vehicle (TTI, 1990). Consumption of fuel, oil, and tires are all reduced as speed increases, and reductions are especially significant for each unit increase in mph at very low speeds. For trucks on flat terrain, an increase from $10 \mathrm{mph}$ to $15 \mathrm{mph}$ reduces fuel consumption roughly 50 gallons per 1,000 miles. The same increase in speed reduces oil consumption by 10 quarts per 1,000 miles. 
Figure 2-3. Truck fuel consumption versus velocity

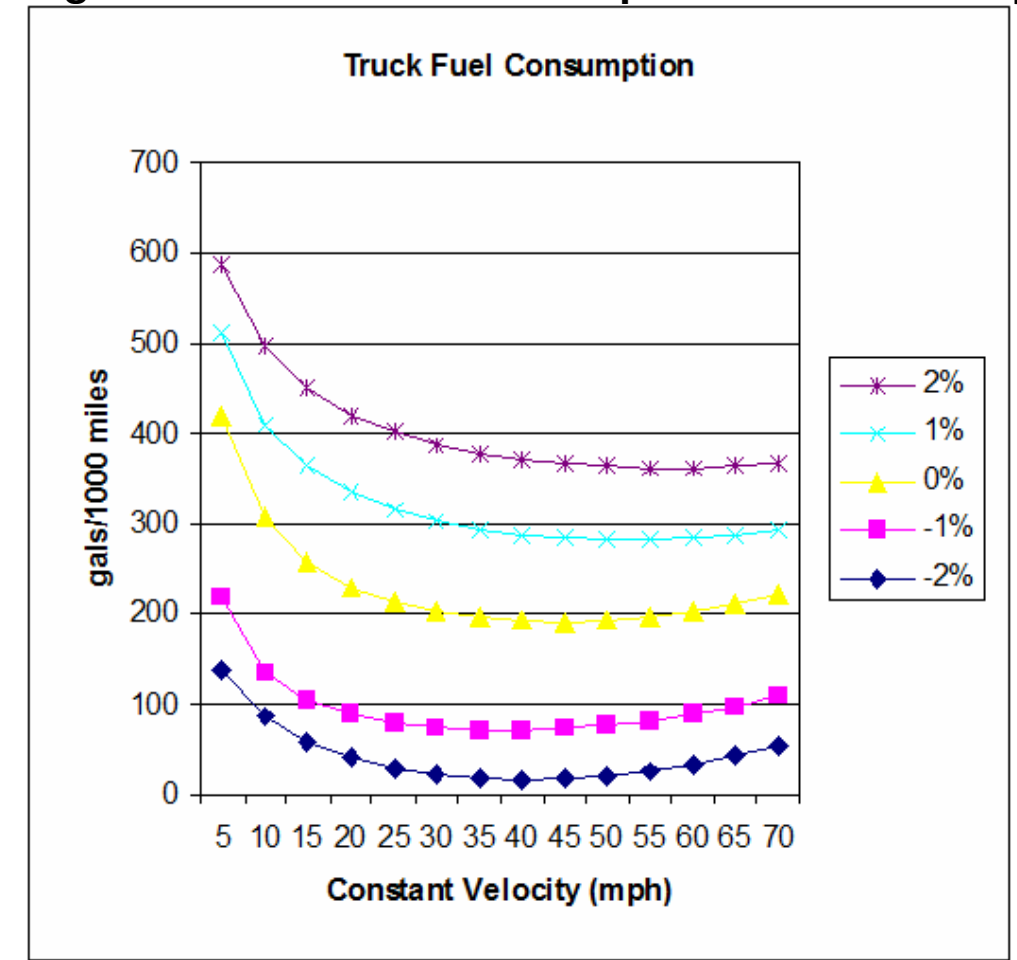

Source: Texas Transportation Institute, 1990

Figure 2-4. Truck oil consumption 


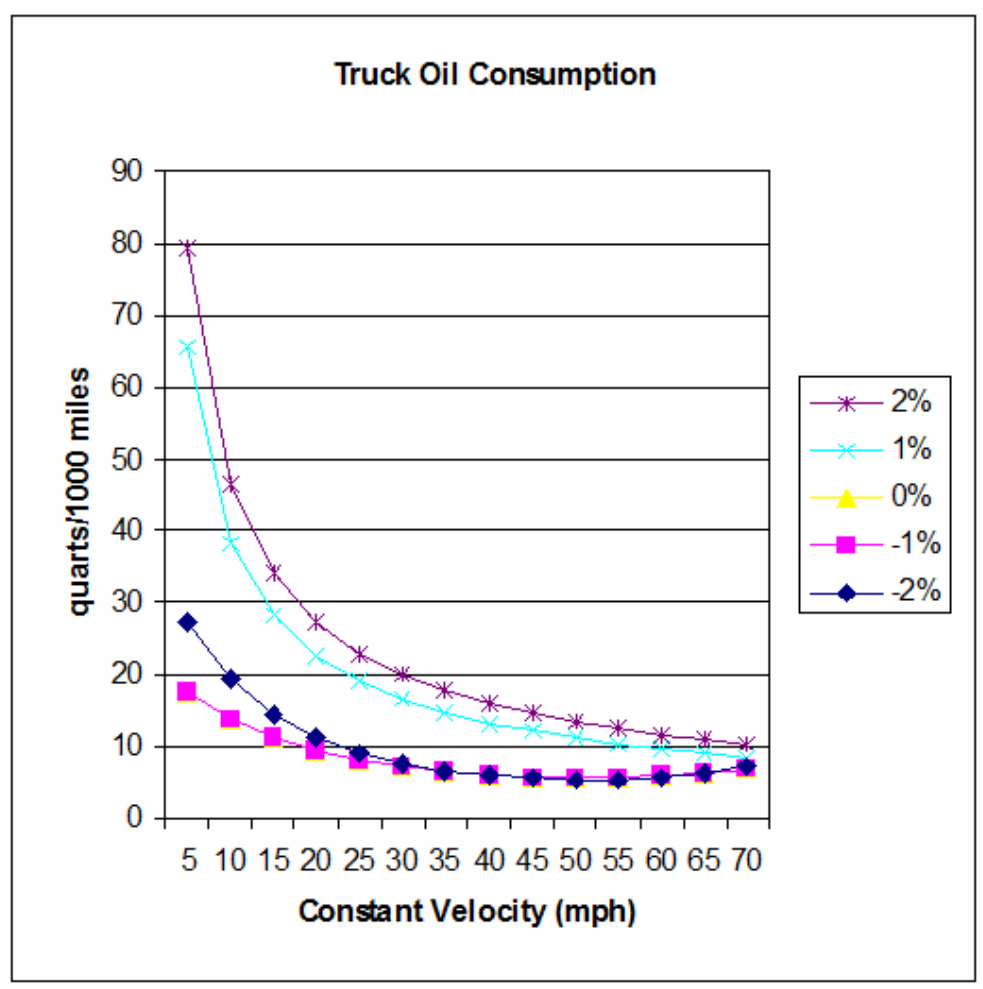

Source: Texas Transportation Institute, 1990

\section{Conclusion}

The literature shows that generally a benefit is derived from reducing the number of bus stops along the route. Though consolidation on its own may not represent an extremely large time savings, when combined with additional transitoriented measures, it can represent a significant travel time savings. Consolidation should make passenger boarding and alighting more predictable which can increase the reliability of transit service. There will also be cost savings per route which can be large considering the length and frequency of many of the routes in San Francisco. The combined savings over all of the routes will be significant and can be used to increase service or add amenities along routes that 
will in turn reduce bus travel times and make service more convenient for the customer. 


\section{CHAPTER 3: BEST PRACTICES RESEARCH}

The following research looks at cities and various organizations to determine best practices in the industry. It looks at bus stop spacing standards and the rationale behind standards. There is also research on access and acceptable walking distances to transit as well as on how transit agencies can involve citizens in bus stop spacing programs.

\subsection{Factors in Placing Bus Stops}

\section{Close stops versus stops farther apart}

Many agencies and research from TCRP 19 (TTI, 1996) discuss the tradeoffs of locating bus stops closer or farther apart. Figure 3-1 depicts this trade-off. Providing stop locations which are close together leads to longer route travel times. Comparing the diagrams of close stops and stops that are father apart shows that when stops are placed very close together, even as close as 800 feet, there is significant overlap in the walking distance access zones for each stop. The access zones in Figure 3-1 represent an eighth of mile from each stop location, and each access zone is approximately 50 percent overlapped by adjacent access zones. Increasing the spacing between stops, in this example, increase access distance for some locations, but most areas remain within 1/8 of a mile from a bus stop. 


\section{Figure 3-1. Stop spacing trade-off}

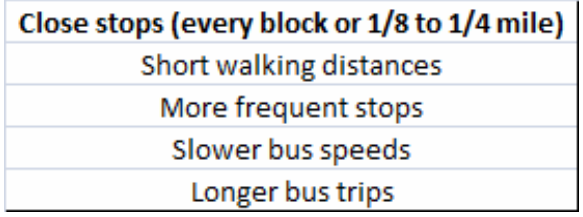

Stops farther apart

Longer walking distances

More infrequent stops

Higher bus speeds

Shorter bus trips

Source: TCRP 19 (TTI, 1996)

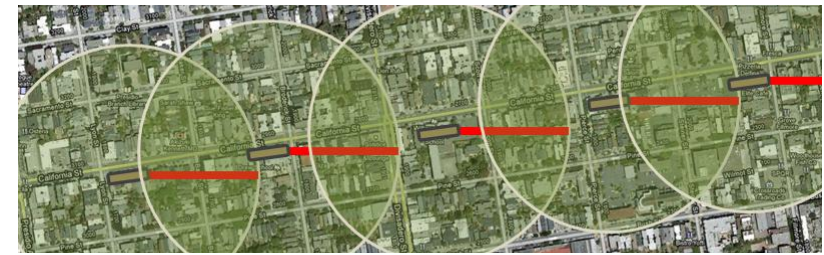

Example Diagram: Bus stops approximately $800 \mathrm{ft}$. apart with $1 / 8$ mile access zones

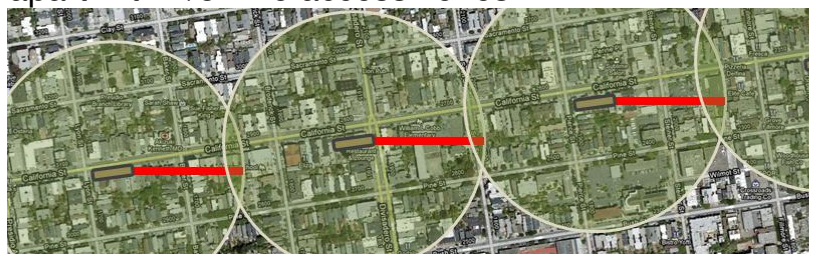

Example Diagram: Bus stops approximately $1200 \mathrm{ft}$. apart with $1 / 8$ mile access zones

\section{Operations-focused factors}

TCRP 19 (TTI, 1996:20) also gives many criteria for placing a stop. These guidelines are meant for the initial stop placement when designing a route, not alterations to existing routes, but are factors to consider for the final stop methodology in this research. The factors fall into three major areas: the needs of passengers using the route, characteristics of the street on which the route will fall, and existing sites with bus priority features or potential for bus priority. The Stop Placement Criteria are shown in Table 3-1. 


\section{Table 3-1. TCRP stop placement criteria and explanation}

\begin{tabular}{|l|l|}
\hline \multicolumn{1}{|c|}{ Stop Placement Criteria } & \multicolumn{1}{c|}{ Explanation } \\
\hline $\begin{array}{l}\text { Adjacent land use and } \\
\text { activities }\end{array}$ & $\begin{array}{l}\text { Densely populated areas or } \\
\text { commercial node }\end{array}$ \\
\hline Bus routing & $\begin{array}{l}\text { Example: Consider if bus is } \\
\text { turning at intersection }\end{array}$ \\
\hline Bus signal priority & $\begin{array}{l}\text { Extended green suggests far } \\
\text { side placement }\end{array}$ \\
\hline $\begin{array}{l}\text { Impact on intersection } \\
\text { operations }\end{array}$ & $\begin{array}{l}\text { Is there heavy traffic in one } \\
\text { direction which stop will impact }\end{array}$ \\
\hline Intersecting transit routes & Encourage transfer points \\
\hline Intersection geometry & $\begin{array}{l}\text { Wider or narrower street or } \\
\text { lanes can create bus priority }\end{array}$ \\
\hline $\begin{array}{l}\text { Parking restrictions and } \\
\text { requirements }\end{array}$ & $\begin{array}{l}\text { Bus zones may remove } \\
\text { parking }\end{array}$ \\
\hline $\begin{array}{l}\text { Passenger origins and } \\
\text { destinations }\end{array}$ & $\begin{array}{l}\text { Why are passengers using the } \\
\text { route? }\end{array}$ \\
\hline Pedestrian access & $\begin{array}{l}\text { Accessibility for } \\
\text { handicap/wheelchair patrons }\end{array}$ \\
\hline Physical roadside constraints & Trees, poles, driveways, etc. \\
\hline Potential patronage & $\begin{array}{l}\text { Locations of significant } \\
\text { passenger densities or traffic }\end{array}$ \\
\hline Presence of bus bypass lane & $\begin{array}{l}\text { Routes should take advantage } \\
\text { of exisiting infrastructure }\end{array}$ \\
\hline Traffic control devices & $\begin{array}{l}\text { Bus stops placed nearside at } \\
\text { Stops and farside at Signals }\end{array}$ \\
\hline
\end{tabular}

\section{Pedestrian-focused factors}

Transport for London [TFL] (2006) also gives the following consideration for the locations of bus stops:

- Driver and prospective passengers are clearly visible to each other

- Adequate footway width

- Away from sites likely to be obstructed

- Close to pedestrian crossings

- Where there is space for a bus shelter

- Sited to minimize walking distance to interchanges

- Close to main junction without affecting safety or junction 
The TCRP 19 guidelines focus on existing infrastructure as well as passenger use of the transit system. TFL (2006) emphasizes accessibility and appropriateness of the site for pedestrians. The placement of all stops depends on the site of the individual stop itself (TriMet, 2002:5), and even with a methodology to guide general stop placement decisions, each stop should be given individual consideration.

\section{Farside and nearside stops}

TRCP 19 (TTI, 1996) shows the advantages and disadvantages associated with various sitings of stop locations (Table 3-2). The terms far-side and near-side refer to locations with respect to an intersection. As a bus approaches an intersection, a stop location before passing through the intersection is a near-side stop. A stop location immediately after the bus passes through the intersection is a far-side stop. Any stop in between these areas is considered a mid-block stop.

\section{Additional considerations}

When considering consolidation of stops, an agency needs to look not only at adequate sites for stops, but also if the stop removal will adversely impact a disadvantaged group, such as the transit-dependent, elderly, or disabled (TriMet, 2002:5). Additionally, stops should not change often to make the system more predictable, so whatever choices are made should remain in effect for 5 to 10

years. Because of more specific local knowledge, public input may be appropriate 
for determining which stop removals will have a significant adverse effect or to

identify issues that may be associated with the placement of a particular stop.

Table 3-2. Considerations for siting stops far-side, near-side, or mid-block

\begin{tabular}{|c|c|c|}
\hline & Advantages & Disadvantages \\
\hline $\begin{array}{l}\text { Far- } \\
\text { Side } \\
\text { Stop }\end{array}$ & $\begin{array}{l}\text { - Minimizes conflicts between right turning } \\
\text { vehicles and buses } \\
\text { - Provides additional right turn capacity by } \\
\text { making curb lane available for traffic } \\
\text { - Minimizes sight distance problems on } \\
\text { approaches to intersection } \\
\text { - Encourages pedestrians to cross behind the } \\
\text { bus } \\
\text { - Creates shorter deceleration distances for } \\
\text { buses since the bus can use the intersection } \\
\text { to decelerate } \\
\text { - Results in bus drivers being able to take } \\
\text { advantage of the gaps in traffic flow that } \\
\text { are created at signalized intersections }\end{array}$ & $\begin{array}{l}\text { - May result in the intersections being } \\
\text { blocked during peak periods by stopping } \\
\text { buses } \\
\text { - May obscure sight distance for crossing } \\
\text { vehicles } \\
\text { - May increase sight distance problems for } \\
\text { crossing pedestrians } \\
\text { - Can cause a bus to stop far side after } \\
\text { stopping for a red light, which interferes } \\
\text { with both bus operations and all other } \\
\text { traffic } \\
\text { - May increase number of rear-end accidents } \\
\text { since drivers do not expect buses to stop } \\
\text { again after stopping at a red light } \\
\text { - Could result in traffic queued into } \\
\text { intersection when a bus is stopped in travel } \\
\text { lane }\end{array}$ \\
\hline $\begin{array}{l}\text { Near- } \\
\text { Side } \\
\text { Stop }\end{array}$ & $\begin{array}{l}\text { - Minimizes interferences when traffic is } \\
\text { heavy on the far side of the intersection } \\
\text { - Allows passengers to access buses closest } \\
\text { to crosswalk } \\
\text { - Results in the width of the intersection } \\
\text { being available for the driver to pull away } \\
\text { from curb } \\
\text { - Eliminates the potential of double stopping } \\
\text { - Allows passengers to board and alight } \\
\text { while the bus is stopped at a red light } \\
\text { - Provides driver with the opportunity to } \\
\text { look for oncoming traffic, including other } \\
\text { buses with potential passengers }\end{array}$ & $\begin{array}{l}\text { - Increases conflicts with right-turning } \\
\text { vehicles } \\
\text { - May result in stopped buses obscuring } \\
\text { curbside traffic control devices and } \\
\text { crossing pedestrians } \\
\text { - May cause sight distance to be obscured } \\
\text { for cross vehicles stopped to the right of } \\
\text { the bus } \\
\text { - May block the through lane during peak } \\
\text { period with queuing buses } \\
\text { - Increases sight distance problems for } \\
\text { crossing pedestrians. }\end{array}$ \\
\hline $\begin{array}{l}\text { Mid- } \\
\text { block } \\
\text { Stop }\end{array}$ & $\begin{array}{l}\text { - Minimizes sight distance problems for } \\
\text { vehicles and pedestrians } \\
\text { - May result in passenger waiting areas } \\
\text { experiencing less pedestrian congestion }\end{array}$ & $\begin{array}{l}\text { - Requires additional distance for no-parking } \\
\text { restrictions } \\
\text { - Encourages patrons to cross street at } \\
\text { midblock (jaywalking) } \\
\text { - Increases walking distance for patrons } \\
\text { crossing at intersections }\end{array}$ \\
\hline
\end{tabular}

Source: TCRP 19 (TTI, 1996) 


\subsection{Bus Stop Spacing Standards in The US}

In recent years, many transit agencies in the US began to develop stop spacing standards. This is in part an attempt to repeat the successes that European cities have had in maintaining a high transit mode share. The standards act as guidelines which help agencies determine where stops are needed or where consolidation is needed. TCRP 19 (TTI,1996) shows typical stop spacing (Table 3-3) based on the type of environment or density of an area. The spacing range shows there is a wide variation in stop spacing standards among cities.

Table 3-3. Typical stop spacing

\begin{tabular}{|l|c|c|}
\hline \multicolumn{1}{|c|}{ Environment } & Spacing Range & Typical Spacing \\
\hline Central Core Areas of CBDs & 300 to 1000 feet & 600 feet \\
\hline Urban Areas & 500 to 1200 feet & 750 feet \\
\hline Suburban Areas & 600 to 2500 feet & 1000 feet \\
\hline Rural Areas & 650 to 2640 feet & 1250 feet \\
\hline
\end{tabular}

Source: TCRP 19 (TTI, 1996)

Table 3-4 contains a list of guidelines developed for different cities. In most cases, a range of values is given for the distance between stops. TriMet has guidelines based on density (units per acre). It states that stops in dense areas should not be less than 780 feet apart, and stops in less dense areas should not be less than 1000 feet apart. Seattle has guidelines for local routes to give 4 to 6 stops per mile, with a maximum of 8 stops per mile. Stops should not be less than 500 feet apart. Omnitrans in San Bernardino County says stops should be 750 to 900 feet apart in high or medium density areas. Chicago has one of the shortest 
stop spacing recommendations for routes, 660 feet, made to match the block structure of the area.

The recommended ranges for high density areas fall between 780 to 1320 feet for local routes. Express or rapid routes can have stops between 1700 feet and 1 mile apart. San Francisco's proposed new stop policy would have longer minimum and maximum recommended stop spacing than other cities, however San Francisco has a policy of allowing closer bus stops on steeper grades.

Table 3-4. Standards for various cities

\begin{tabular}{|c|c|c|}
\hline Location & Feet Between Stop & Stops per mile \\
\hline San Francisco (Proposed) & 900 to 1400 & 3 to 6 \\
\hline Grade $>10 \%$ & Minimum of 500 & \\
\hline Portland (Tri-Met) & Should not be less than & \\
\hline Dense area (22units/acre) & 780 & 6 to 7 \\
\hline (4 to 22 units/acre) & 1000 & 5 \\
\hline \multicolumn{3}{|l|}{ Seattle (King County Transit) } \\
\hline \multirow{3}{*}{ Local } & 880 to 1320 & 4 to 6 \\
\hline & Minimum of 660 & Maximum of 8 \\
\hline & No less than 500 & \\
\hline \multicolumn{3}{|l|}{ San Bernardino (Omnitrans) } \\
\hline CBD & 1000 & 5 \\
\hline High to Medium Density & 750 to 900 & 5 to 7 \\
\hline Medium to Low Density & 900 to1300 & 4 to 5 \\
\hline \multicolumn{3}{|l|}{ Chicago (Transit Authority) } \\
\hline Local & Every $1 / 8$ mile (660) & 8 \\
\hline Local & No more than 1320 & \\
\hline Express & $1 / 2$ to 1 mile & 1 to 2 \\
\hline \multicolumn{3}{|l|}{ Alameda County (AC Transit) } \\
\hline Local & 800 to 1300 & 4 to 7 \\
\hline Rapid & 1700 to 5000 & 1 to 3 \\
\hline
\end{tabular}

Source: AC Transit (1989); Chicago Transit Authority (2001); SFMTA (2009a); TriMet (1989); Municipality of Metropolitan Seattle (1991).

${ }^{*}$ The values given in guidelines are shown above. Italicized values are conversions based on the published guidelines which can be used for comparisons between different types of guidelines. 


\subsection{International Bus Stop Spacing Standards}

Table 3-5 shows examples of stop spacing outside the US. As stated in ElGeneidy et al. (2005):

"Furth and Rahbee (2000) observe that stops in northern European cities are spaced much further apart than in comparable U.S settings, yet the European transit systems are still able to capture a greater share of the urban travel market. Reilly (1997) also found that the common European practice was to space stops at 3-4 per mile compared to the U.S. practice of 7-10 per mile."

The Transport for London Bus Stop Accessibility Guidelines (2006)

recommend 400m ( 1310 feet) as a good approximate stop spacing distance. The Curitiba bus system (Curitiba, 2003) uses a longer stop spacing distance of $500 \mathrm{~m}$ ( 1640 feet). It cites the stop distance as the limiting factor for the speed of the bus, as buses run in an exclusive right-of-way.

Table 3-5. International stop spacing examples

\begin{tabular}{|l|c|c|}
\hline Location & Feet Between Stop & Stops per mile \\
\hline European average & $1320-1760$ & 3 to 4 \\
\hline London, UK (TFL) & $1310(400 \mathrm{~m})$ & 4 \\
\hline Curitiba, Brazil & $1640(500 \mathrm{~m})$ & 3 \\
\hline
\end{tabular}

Source: Furth and Rabee, 2000; TFL, 2006; Curitiba, 2003

The difference between these guidelines and those by US agencies is clear. Though these cities do not recommend a minimum or maximum, the average stop spacing is in most cases higher than the maximum recommended stop spacing in many US cities. European transit systems have higher market shares, and many elderly or disabled persons are able to use the routes. One reason could be the relatively high cost of gas in most European countries 
compared to the US, however, different transit systems have developed as well. The reason behind the development of different systems in Europe and the US is political according to Furth and Rahbee (2000). Services in the US have fewer guidelines for stop spacing, and in some cases, any stop requests were fulfilled without further consideration. There are political benefits to placing a bus stop in a neighborhood because it is a direct, local, and visible action. However, the overall impact of placing stops wherever they are requested is a decrease of bus speeds across the course of the route (Furth and Rahbee, 2000). This is a large subject of debate which will not be dealt with here, but this means that we cannot assume that American standard stop spacing is best able to serve customers.

\subsection{Access to Bus Stops}

Many documents (TriMet, 2002) specify that $1 / 4$ mile is the acceptable distance that a person should have to walk to a bus stop. During off peak or night services, $1 / 2$ mile to 1 mile (Chicago Transit Authority [CTA], 2001) are considered optimal distances. Information supporting pedestrian access (Pedestrian and Bicycle Information Center, 2009) also states that $1 / 4$ to $1 / 2$ mile is the distance people will walk to access transit. An example of a typical walking distance policy from CTA is shown here:

CTA Walking Distance to Service (CTA, 2001)

As was mentioned under Service Coverage, it is the Authority's policy to have service available to almost all residents in CTA's service area within a $1 / 2$ mile walking distance during the weekday peak period, $1 / 4$ mile in high density areas. These walking distances expand during the midday, 
evenings, weekends, and owl periods due to a reduction in the level of passenger demand at these times. Demand generators, such as residential concentrations, shopping centers, factories, and schools that are not within a $1 / 2$ mile walking distance to a bus route and have streets capable of supporting bus service, will be considered for service if there is potential ridership.

Chicago also shows service coverage for the entire system. This considers both walking distance and the distance between routes (Table 3-6). The issue of service coverage is not added into the methodology because at present San Francisco has extensive transit coverage (Figure 4-1 and Figure 4-2).

Table 3-6. CTA stop coverage

\begin{tabular}{|lll|}
\multicolumn{3}{c|}{ Guideline for Bus Grid System } \\
\hline & DISTANCE & TYPICAL WALK \\
TIME PERIOD & BETWEEN ROUTES & DISTANCES \\
Weekday peak & & \\
$\quad$ High Density & $1 / 2$ mile & $1 / 4$ mile \\
$\quad$ Low Density & 1 mile & $1 / 2$ mile \\
Weekday Midday/Evening & 1 mile & $1 / 2$ mile \\
Saturday and & 1 mile & $1 / 2$ mile \\
Sunday/Holidays & & 1 mile \\
Owl & 2 miles & 1 \\
\hline
\end{tabular}

Source: CTA, 2001

\subsection{Disabled Persons and Elderly}

Transit agencies must accommodate the needs of the elderly or disabled. TriMet states that if a stop is used frequently by the disabled or elderly, the stop should be retained. King County Transit (Municipality of Metropolitan Seattle, 1991) says that priority is given to bus stops for the disabled/elderly, and stops should not be moved unless there is an equal or better stop to serve their needs. Omnitrans (Darnell, 2006) states that the needs of the disabled, elderly, and children should be met. 
TriMet's policy on accessibility (2002)

Where reasonable, bus stops should be accessible. Americans with Disabilities Act (ADA) considerations will be given top priority in the siting and design of new and existing bus stops.

Information regarding ADA in the TCRP report 19 (TTI, 1996) states that

while transit agencies are not required to fix existing stops to accommodate ADA needs, clear access should be provided to the stop locations. The law applies to having access to the site and transit agencies buying accessible vehicles, but does not directly address stop location (US DOT, 2005). However, undue burden cannot be placed on the elderly or disabled by future transit decisions.

\subsection{Standard Adoption}

Cities adopt standards based on those adopted elsewhere and perceived suitability for their own conditions. This is done by either a committee or a team, and presented as an informative document. For TriMet and CTA, the documents were approved by the Transit Authority Board. In no case are these guidelines considered requirements. Stop locations do not need to conform to the guidelines, if the circumstances require different treatment.

\subsection{Public Participation}

Public participation is as important in transportation planning as it is in planning in general. Traditional practices of public participation include stakeholder interviews, community roundtables, surveys, public open houses 
information activities, and focus groups. There is extensive research in this area, and the following paragraphs look at methods and issues that may apply to the stop consolidation project for SFMTA.

Some of the commonly used participation techniques include newsletters, brochures, meetings, and working with small groups, though the commonly used techniques are not always effective (Hopes, Kramer, and William, 2006). They found that public involvement is considered most effective when there is a forum for interaction and exchange of ideas. The authors recommend the following:

- Meetings should be taken to where people gather, rather than relying on the community to come to the planners.

- An effort should be made to involve the public early in the process.

- Planners should involve the public rather than lecture to the public. There is a common perception that many decisions are made prior to public outreach.

- Planners also have the task of communicating large amounts of information in an understandable way and showing the community why they should be interested in a particular project.

One example of involving the community in transportation related decisions looked at revitalization along San Pablo Avenue, which run through many cities in the San Francisco Bay Area (McAndrews, Florez, and Deakin, 2006). First, site research was done on physical, social, and economic factors affecting the area. 
This data was then used to develop surveys to ask the community what should be changed and what should be retained along the corridor. The survey data was used to create topics for the focus groups. The focus groups helped in providing information to explain apparent contradictions in the survey data. These efforts found that the community favored local-serving mixed use areas, versus the vision of planners to develop the corridor into a major regional destination.

A similar issue arose with the community input on a freeway project in Los Angeles (Chaves, Garcia, and Gilmore, 2006). Though public outreach was done through traditional methods of stakeholder interviews, roundtables, and questionnaires, the final alternatives developed, which included the technical analysis, were all rejected by the public. The Los Angeles County Metropolitan Transportation Authority asked for a better public process in developing the project. A two-tiered system for consensus-building was developed that allowed community leaders and experts to discuss various issues related to the project. The main criteria developed for evaluating the effectiveness of public participation are representativeness, creative thinking, fully exploring issues, shifts in how issues were discussed, participant satisfaction with the process, and how the consensus-building process informed the final policy. The study shows that perspectives changed about major issues through the discussion process. Many different groups were represented and the process produced solutions, though some people felt their results should have had a greater influence on the final product. These examples can inform the development of a public participation process for stop consolidation. 
TriMet's (El-Geneidy et al., 2005) approach which involved breaking routes into segments, identifying key locations along the route, and 'filling in' other stops as appropriate, can be combined with public outreach to guide proposal development. The Washington Metropolitan Area Transit Authority (WMATA) included public outreach to guide the decision-making process for improving service along one route (WMATA, 2009). A rider survey was conducted to understand how the service is used. The questions included the following topics:

- Stops where customers board and alight

- Direction of travel

- Time of day

- Transfer activities; from another line or to another line

- How often the line is used

- Rating of service quality

The data collected from these surveys was used to inform the first public meeting. This meeting involved discussions to identify issues that should be addressed in order to improve service along the line. After the issues were identified, solutions were developed, and four concepts for route improvement were proposed. The second meeting involved a discussion of these concepts in small groups. They spoke about advantages and disadvantages as well as additional issues to address. This project is ongoing, and has a different scope than the bus stop consolidation program, however, the process used here documents possible outreach activities that SFMTA may use. 


\section{CHAPTER 4: CONSOLIDATION PROCESS}

This chapter first shows issues in the development of consolidation criteria. Second, the methodology for developing consolidation proposals is explained. Third, a case application is presented for Route 1 California, along with an evaluation of the before and after effects of the stop consolidation on the buses and customers.

\subsection{General Issues}

\section{Accessibility}

Though SFMTA is analyzing the reduction of the number of bus stops along the route, the goal is not to create access barriers to transit. There is a trade-off between transit coverage and transit functionality. This is why standards and research from around the country and the world are being used to develop bus stop spacing standards for San Francisco. Stop proposals can be changed to maintain or create stops that serve the elderly or disabled.

\section{Proximity to major activity centers}

For a bus route to be useful, it must stop at places that attract riders. The present stop configuration means that most blocks have stops. Stops which serve activity centers or important locations should not be considered for elimination. 


\section{Transfers}

Part of having a successful transit system is being able to access most transfer points. There are many possible transfer points on many of the routes in San Francisco. Not every transfer can be a direct transfer if stop spacing is to be effective, so transfer points are marked as either primary or secondary. These designations can also change based on public input.

\section{Existing bus stops and shelters}

Literature shows that bus stops should remain in place unless there is a need to move or remove them. This reduces the amount of confusion around the changing of stops. In addition, stops where there are amenities in place will be more difficult to change. Bus shelters are not owned by the SFMTA, nor are they built by the agency. While bus shelters can be taken away or added theoretically wherever necessary, the agency must coordinate with an outside marketing agency to change stops. This affects the timing of bus shelter building and removal and the number of changes that can be made at any specific time.

\section{High ridership stops}

Stops that pick up many riders should remain in place. In cases where there are many high ridership stops in a row, other factors can determine which stops should remain, such as the facilities available at each stop. Stops should serve locations where there is high ridership but also destinations that are important. 


\subsection{Methodology}

\section{Analysis of network walking distances}

The research presented in this paper shows that people can or should be expected to walk one quarter of a mile to a bus stop location. Maps were developed showing one-eighth, one-quarter, and half mile buffers around bus stops to demonstrate network coverage and overlap and gaps. This is important in establishing a baseline before stop spacing standards are changed.

\section{Analysis process for one bus route}

This portion of the analysis develops an Excel and GIS-based system to create proposals and change them as more information is added to the database. Based on previous research, developing stop spacing changes will follow these steps:

1. Break route into distinct segments based on street pattern. Factors considered in route segmentation include density, character of area, and major thoroughfares.

2. Choose significantly high ridership locations in these areas.

Significantly high ridership is somewhat subjective, and stops can be changed based on community input. These points should not be eliminated without a sufficient alternative. Locations may be marked for: a) high boarding, b) high alighting, c) high total of boarding and alighting. High ridership stops are defined for each segment under 
Step One. Passenger boarding, alighting, and total activity are standardized by segment using the formula:

$$
\mathrm{Z}=\frac{\chi_{i}-\bar{\chi}}{\sigma}
$$

where

$$
\begin{aligned}
\mathrm{Z}= & \text { standardized score } \\
\chi_{i}= & \text { number of boardings, alightings, or total activity } \\
\bar{\chi}= & \text { average number of boardings, alightings, or total } \\
& \text { activity } \\
\sigma= & \text { standard deviation of boardings, alightings, or total } \\
& \text { activity }
\end{aligned}
$$

and

$$
\bar{x}=\frac{\sum_{i=1}^{N} x_{i}}{\mathrm{~N}}
$$

where $\mathrm{N}$ is the number of the stops in the segment

and

$$
\sigma=\frac{\sum_{i=1}^{N}\left(x_{i}-\bar{x}\right)^{2}}{\mathrm{~N}}
$$

where $\Sigma$ is the sum over all stops in the segment

Then stops that meet a threshold of standard deviations above the mean are labeled high ridership stops.

3. Next, key transfer points are marked. Key transfer points are those where there are no other logical alternatives. All key transfer points are 
marked and should not be changed throughout the process unless there is a sufficient alternative.

4. Secondary transfer points are marked where there are many transfer possibilities close together. Any of these options are acceptable alternatives and the final choice can be decided upon through public input.

5. Any locations with existing bus shelters are now marked. There should be an effort to maintain these stops, but they can be moved if necessary.

6. Finally, the slope between stops is used to determine which stop spacing guidelines apply to specific segments of the route.

7. Using this data, stops in between the critical stops are spaced according to the new proposed stop spacing guidelines.

8. The process is repeated for the outbound route and the stops are checked for correspondence between the inbound and outbound routes.

\section{Evaluation of new route proposal}

After developing a route proposal, the route is evaluated in terms of accessibility, cost savings for operations, and fuel and oil consumption. This three-part methodology is illustrated next through an application to one bus route in San Francisco. 


\subsection{Case Application}

\section{Analysis of network walking distances}

Figures 4-1 and 4-2 show all of the bus stops in San Francisco within1/4 mile and 1/8 mile buffers respectively around each of the stops. They illustrate that all but very few locations in San Francisco are within a 1/8 mile of at least one bus stop. Also, almost all locations are within $1 / 4$ of a mile of a bus stop. A close look at the map shows that many of the buffers overlap. This data reveals that there is room for stop consolidation in the system without reducing accessibility to bus stops.

Figure 4-1. 1/4 mile from stop locations

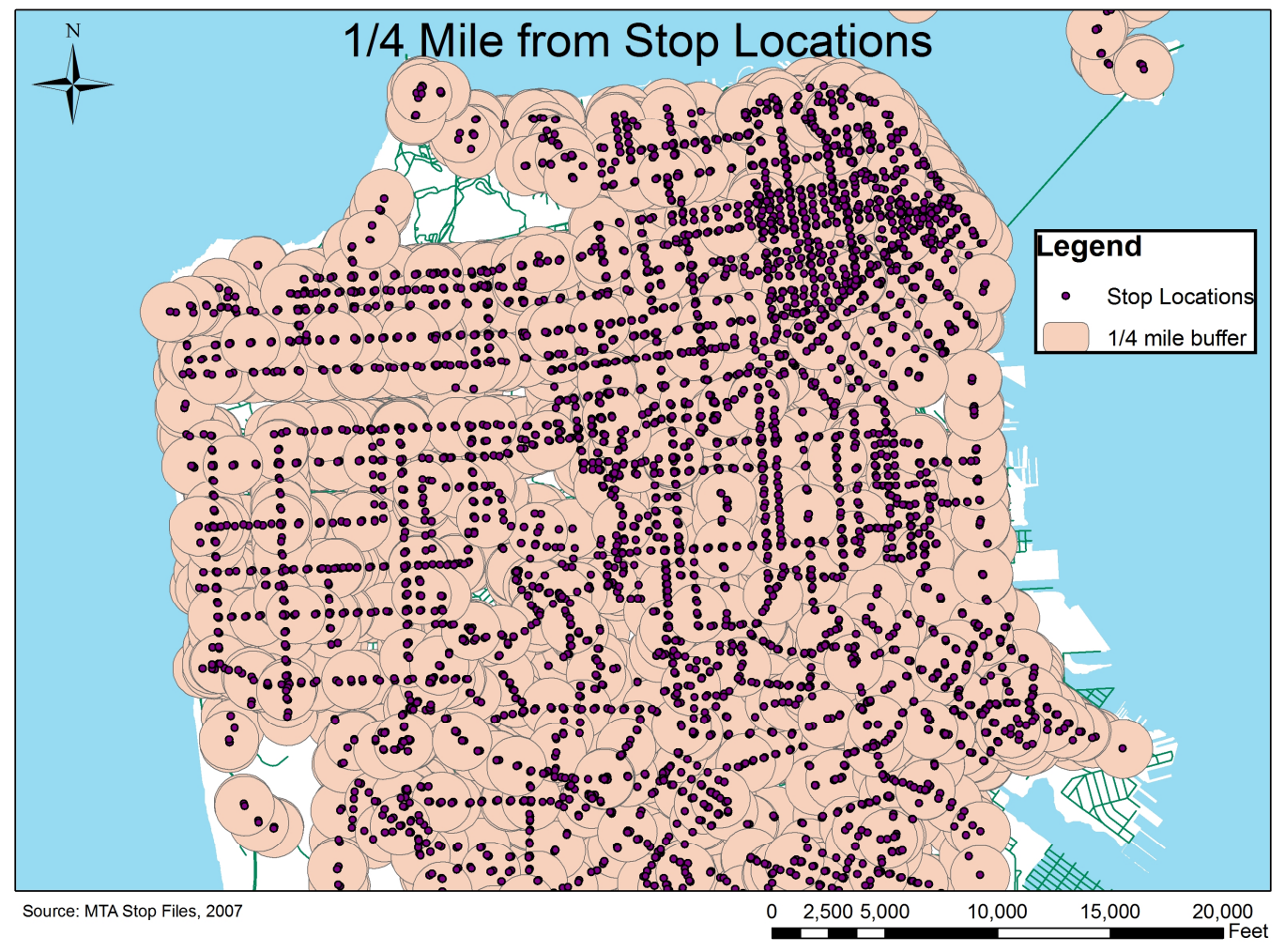


Figure 4-2. 1/8 mile from stop locations

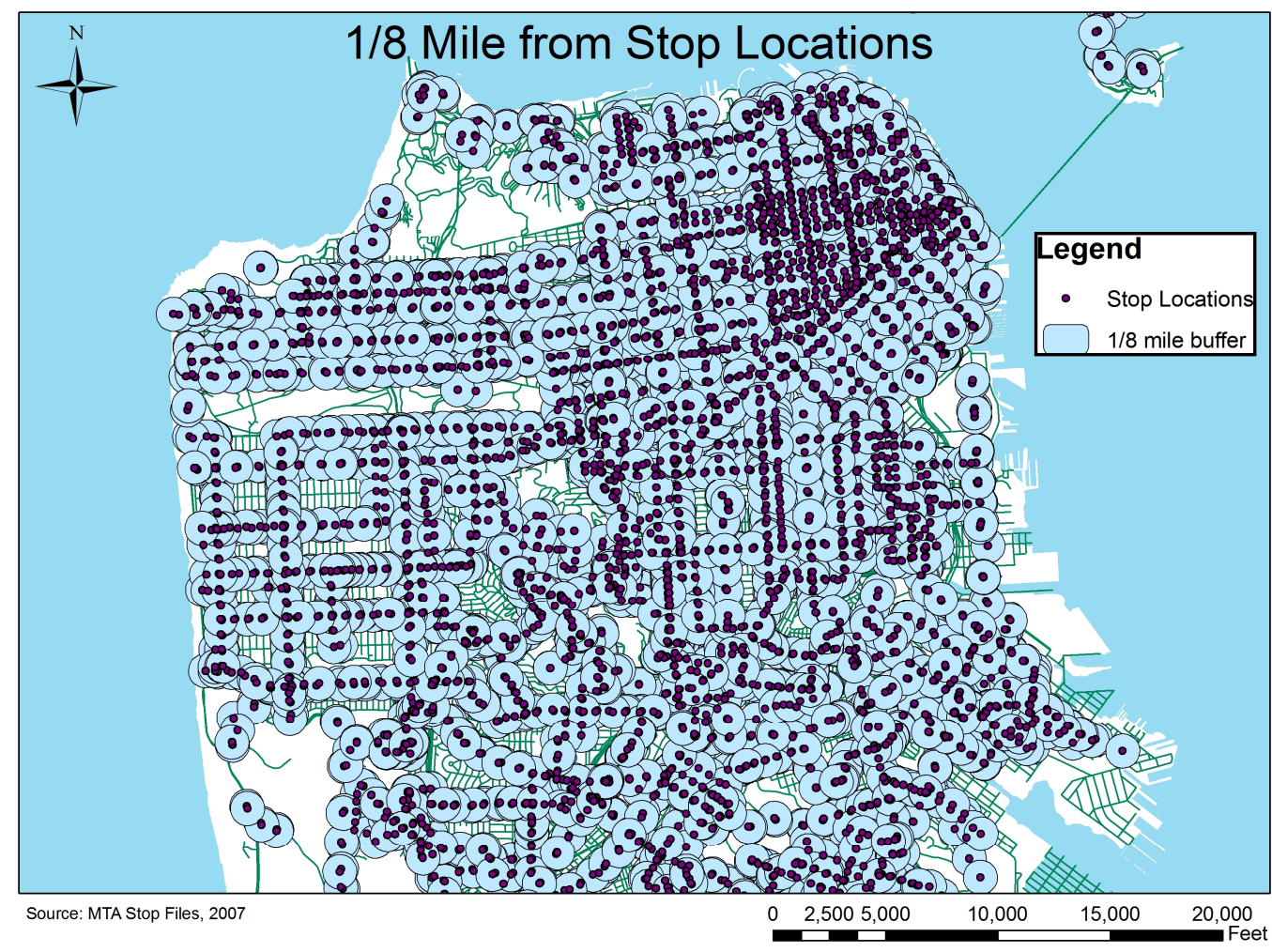

\section{Analysis process for one bus route: Route 1 California Inbound}

The base data is shown in Figure 4-3. The bus stop data compiled by SFMTA includes the following: the route number, inbound or outbound identification, a unique bus stop identification number, a bus stop street name description, additional comments about the site which may affect specific siting of a bus stop, whether the stop is on the nearside or farside of an intersection, the directional position of the stop with regards to an intersection, if the stop is a transfer point, the type of bus stop (flag stop, pole stop, or bus zone), the length of the bus stop if it is a bus zone, the distance between the stop and the stop before it, the slope of the terrain leading to the stop, if the stop has a bus shelter, the average number of daily boardings (ons), daily alightings (offs), and daily activity (total of ons and 
Figure 4-3. Initial Data on Route 1 - California 


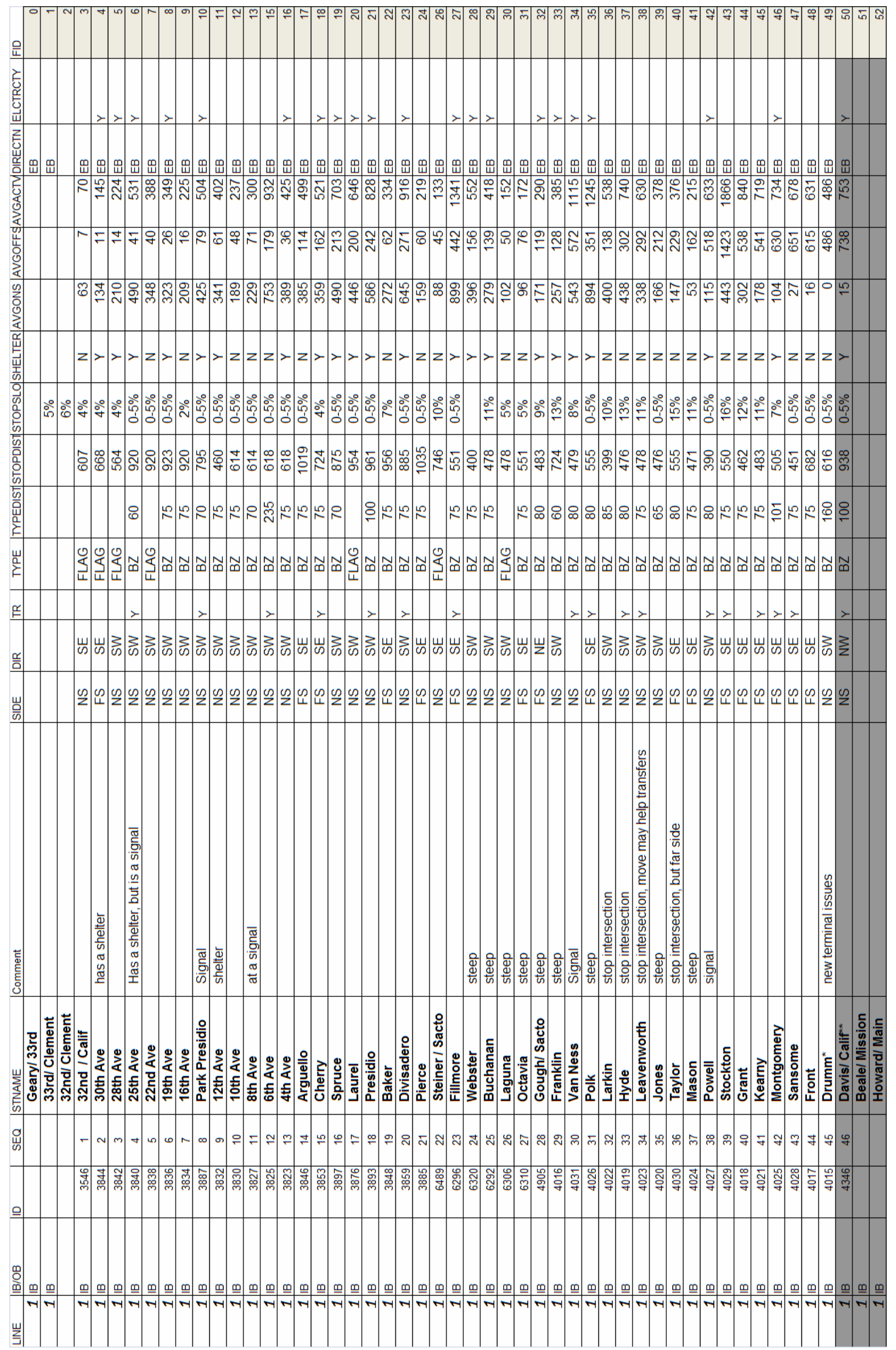


offs) at each stop based on APC data, the direction the route travels, and an additional ID number (FID) used only for this exercise. The data in Figure 4-3 shows the existing route before any changes were made, but due to additional Transit Effectiveness Project (TEP) changes, the final three stops on the route will be eliminated and so will not be included in this analysis. At this point it is also important to note that there is some missing data for a few stops. Field review of these locations was used to determine if the missing data would have major impacts on route proposals. These stops were not determined to be key locations which needed further data.

Step One is dividing the bus route into three segments shown on a map in Figure 4-4 and as data in Figure 4-5. The segmentations were based on fieldwork observations of the physical characteristics of the different areas. The first segment is a relatively flat, residential area with some commercial uses at various stops. The second segment is a hilly area, which is denser and has more commercial uses, and the third segment has very steep hills, and is mostly residential until it approaches the Financial District. 
Figure 4-4. Three segments for analysis

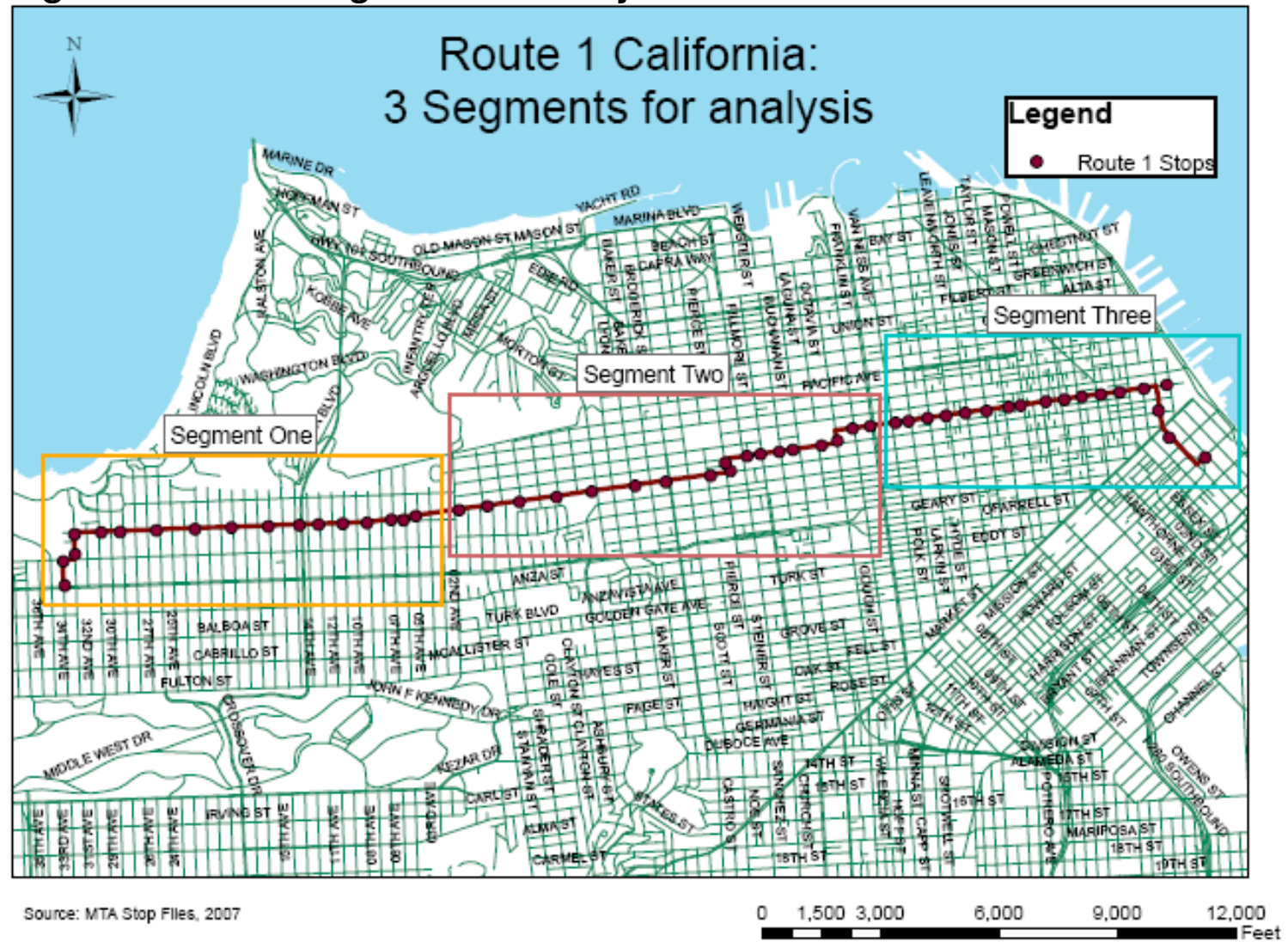

In Step Two, the stops with the highest ridership in each segment are marked. The locations with the highest ridership were determined by finding the standard deviations and converting these to standardized scores (Formula 4.1) for ons, offs, and activity for each of the segments. 
Figure 4-5. Route data divided into segments

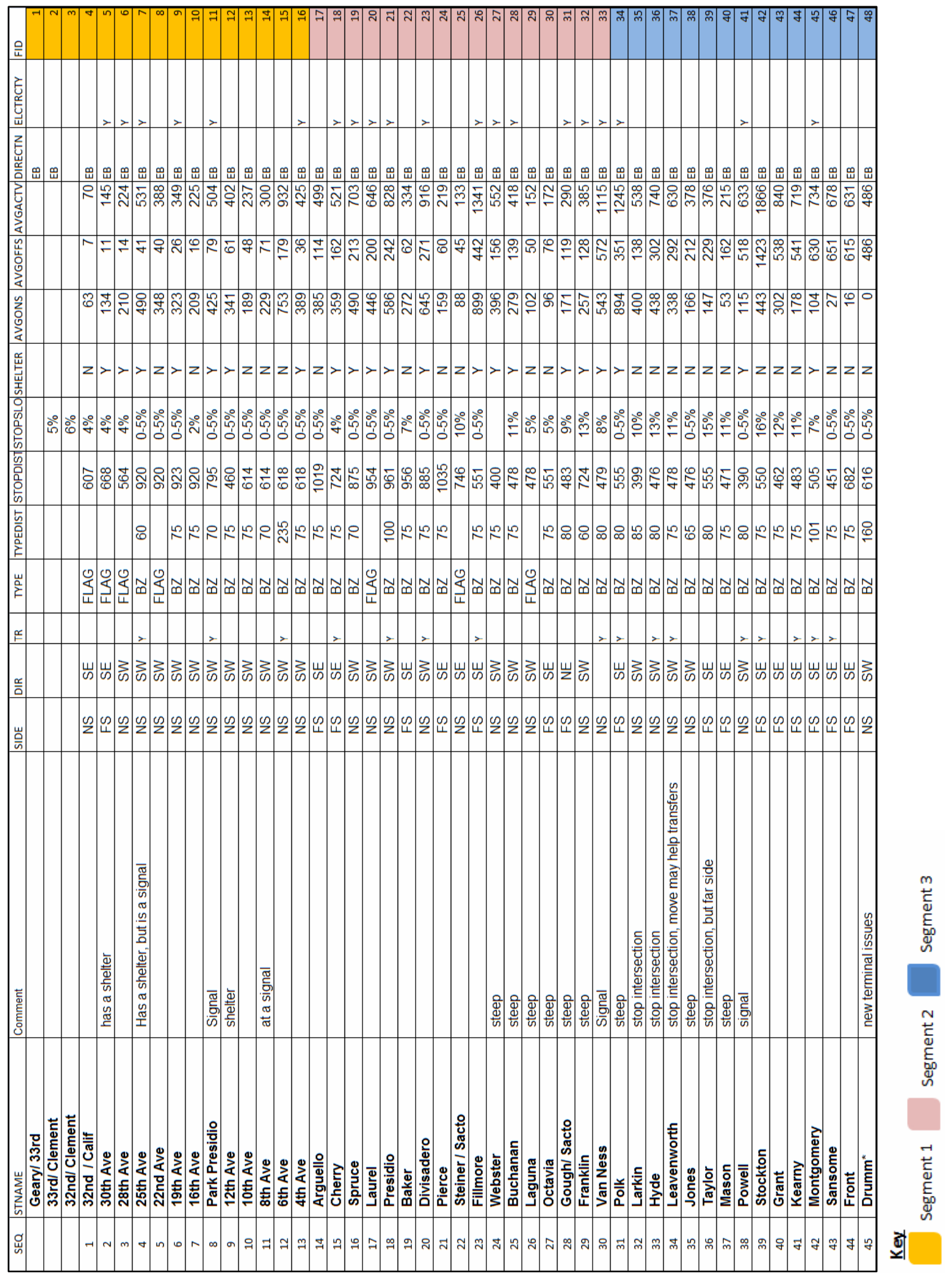


The standardized scores for daily ons, offs, and activity (ons + offs) were computed separately for each segment. These are listed next to the average number of ons, offs, and activity (Figure 4-6, 4-7, and 4-8). The average values and standard deviations are also shown for each group. Stop locations where ridership activity is above one standard deviation of the mean of the segment (for either ons, offs, or overall activity) are considered high ridership stops. These are marked in red in Figures 4-6, 4-7, and 4-8. For this study, high ridership is the major determining factor, however, public input on the stops that should be designated as 'key' locations could change this initial input.

This point is also an opportunity to compare the inbound route to the outbound route. The same methodology was performed using data from the outbound route. The tables with standardized scores are in Appendix 1. There are differences in a few stop locations for the inbound and outbound route. When developing new routes, stops should generally correspond to each other to make routes easy for customers to use. When working with existing routes, planners should attempt to maintain stops that correspond to each other. After comparing the two routes, only one additional stop is marked for the outbound route, Park Presidio. Because this is a transfer point, it will be marked on the inbound route as well. If there were many differences in high ridership stops between inbound and outbound routes, the two lists can be integrated at this point. 
Figure 4-6. Segment 1: Values and standardized scores

\begin{tabular}{|c|c|c|c|c|c|c|}
\hline \multirow[b]{2}{*}{ Stop } & \multicolumn{2}{|l|}{ Segment 1} & \multirow[b]{2}{*}{ Avg Offs } & \multirow[b]{2}{*}{ SD } & \multirow[b]{2}{*}{ Avg Activity } & \multirow[b]{2}{*}{ SD } \\
\hline & Avg Ons & SD & & & & \\
\hline 4 & 63 & -1.47 & 7 & -0.95 & 70 & -1.40 \\
\hline 5 & 134 & -1.06 & 11 & -0.86 & 145 & -1.05 \\
\hline 6 & 210 & -0.61 & 14 & -0.79 & 224 & -0.67 \\
\hline 7 & 490 & 1.02 & 41 & -0.17 & 531 & 0.80 \\
\hline 8 & 348 & 0.19 & 40 & -0.19 & 388 & 0.11 \\
\hline 9 & 323 & 0.04 & 26 & -0.51 & 349 & -0.07 \\
\hline 10 & 209 & -0.62 & 16 & -0.74 & 225 & -0.66 \\
\hline 11 & 425 & 0.64 & 79 & 0.70 & 504 & 0.67 \\
\hline 12 & 341 & 0.15 & 61 & 0.29 & 402 & 0.18 \\
\hline 13 & 189 & -0.74 & 48 & -0.01 & 237 & -0.61 \\
\hline 14 & 229 & -0.50 & 71 & 0.52 & 300 & -0.31 \\
\hline 15 & 753 & 2.55 & 179 & 2.99 & 932 & 2.71 \\
\hline 16 & 389 & 0.43 & 36 & -0.28 & 425 & 0.29 \\
\hline Average & 316 & & 48 & & 364 & \\
\hline SD: & 172 & & 44 & & 209 & \\
\hline
\end{tabular}

${ }^{*}$ Red indicates standard deviation is higher than one.

Figure 4-7. Segment 2: Values and standardized scores

\begin{tabular}{|c|c|c|c|c|c|c|}
\hline \multirow[b]{2}{*}{ Stop } & \multicolumn{2}{|c|}{ Segment 2} & \multirow[b]{2}{*}{ Avg Offs } & \multirow[b]{2}{*}{ SD } & \multirow[b]{2}{*}{ Avg Activity } & \multirow[b]{2}{*}{ SD } \\
\hline & Avg Ons & SD & & & & \\
\hline 17 & 385 & -0.04 & 114 & -0.48 & 499 & -0.18 \\
\hline 18 & 359 & -0.15 & 162 & -0.04 & 521 & -0.12 \\
\hline 19 & 490 & 0.44 & 213 & 0.44 & 703 & 0.44 \\
\hline 20 & 446 & 0.24 & 200 & 0.32 & 646 & 0.27 \\
\hline 21 & 586 & 0.88 & 242 & 0.71 & 828 & 0.83 \\
\hline 22 & 272 & -0.55 & 62 & -0.97 & 334 & -0.69 \\
\hline 23 & 645 & 1.15 & 271 & 0.98 & 916 & 1.10 \\
\hline 24 & 159 & -1.06 & 60 & -0.99 & 219 & -1.04 \\
\hline 25 & 88 & -1.38 & 45 & -1.12 & 133 & -1.31 \\
\hline 26 & 899 & 2.30 & 442 & 2.57 & 1341 & 2.40 \\
\hline 27 & 396 & 0.01 & 156 & -0.09 & 552 & -0.02 \\
\hline 28 & 279 & -0.52 & 139 & -0.25 & 418 & -0.43 \\
\hline 29 & 102 & -1.32 & 50 & -1.08 & 152 & -1.25 \\
\hline 30 & 96 & -0.80 & 76 & -1.18 & 172 & -1.39 \\
\hline 31 & 171 & -0.47 & 119 & -1.05 & 290 & -1.10 \\
\hline 32 & 257 & -0.09 & 128 & -1.02 & 385 & -0.87 \\
\hline 33 & 543 & 1.18 & 572 & 0.34 & 1115 & 0.93 \\
\hline Average & 393 & & 166 & & 559 & \\
\hline SD: & 220 & & 107 & & 326 & \\
\hline
\end{tabular}

${ }^{*}$ Red indicates standard deviation is higher than one. 
Figure 4-8. Segment 3: Values and standardized scores

\begin{tabular}{|c|c|c|c|c|c|c|}
\hline \multirow[b]{2}{*}{ Stop } & \multicolumn{2}{|c|}{ Segment 3} & \multirow[b]{2}{*}{ Avg Offs } & \multirow[b]{2}{*}{ SD } & \multirow[b]{2}{*}{ Avg Activity } & \multirow[b]{2}{*}{ SD } \\
\hline & Avg Ons & SD & & & & \\
\hline 34 & 894 & 2.73 & 351 & -0.34 & 1245 & 1.25 \\
\hline 35 & 400 & 0.54 & 138 & -0.99 & 538 & -0.49 \\
\hline 36 & 438 & 0.71 & 302 & -0.49 & 740 & 0.01 \\
\hline 37 & 338 & 0.27 & 292 & -0.52 & 630 & -0.27 \\
\hline 38 & 166 & -0.49 & 212 & -0.76 & 378 & -0.89 \\
\hline 39 & 147 & -0.58 & 229 & -0.71 & 376 & -0.89 \\
\hline 40 & 53 & -0.99 & 162 & -0.92 & 215 & -1.29 \\
\hline 41 & 115 & -0.72 & 518 & 0.18 & 633 & -0.26 \\
\hline 42 & 443 & 0.73 & 1423 & 2.95 & 1866 & 2.78 \\
\hline 43 & 302 & 0.11 & 538 & 0.24 & 840 & 0.25 \\
\hline 44 & 178 & -0.44 & 541 & 0.25 & 719 & -0.05 \\
\hline 45 & 104 & -0.77 & 630 & 0.52 & 734 & -0.01 \\
\hline 46 & 27 & -1.11 & 651 & 0.58 & 678 & -0.15 \\
\hline 47 & 16 & -1.16 & 615 & 0.47 & 631 & -0.26 \\
\hline 48 & 0 & -1.23 & 486 & 0.08 & 486 & -0.62 \\
\hline Average & 277 & & 461 & & 738 & \\
\hline SD: & 226 & & 326 & & 406 & \\
\hline
\end{tabular}

${ }^{*}$ Red indicates standard deviation is higher than one.

In Step Three (Figure 4-9), transfer locations, if they differed from high ridership stops were marked as key locations. If there were two successive transfer points, one was determined to be more critical than the other. First, if the distance separation between the two transfer stops was acceptable according to the new stop spacing guidelines, then both would be marked. If the distance of separation was less than the guideline, depending on the slope, then a map was used to determine which transfer options were available. If both locations offer the same transfers, then ridership determines which stop location should be marked (Figure 4-9). The transfer points which are not marked as critical are marked as alternative transfer points (Figure 4-10). This portion can also be determined by community input. 
After transfer locations were marked, locations with existing shelters were marked (Figure 4-11). Preference is given to these locations though it is not necessary to keep the stops where there are existing shelters. Finally, based on distance between stops, slope, and the proposed stop policy, the remaining stops were chosen from the list of existing stops. This process eliminated ten stops out of 48 stops on the inbound route (Figure 4-12).

The new set of stops (Figure 4-15) was then used to produce a map comparing the access area of the new route with the old route (Figure 4-13 and 414). These show that there is very little change in the $1 / 4$ mile coverage area after the stops are removed. There is also very little change in the $1 / 8$ mile coverage area with the new stop list. The reduction of stops mainly reduced the amount of overlap of coverage for each individual stop.

\section{Alternative approaches}

The process described above can be used in different ways to achieve a similar result. The ranking of priorities starting with high ridership locations and transfers, and including existing shelters, may be changed in accordance with agency goals and the character of the area for which a bus system is being developed or improved. Other priorities can take precedence, such as senior centers or school facilities. 
Figure 4-9. High ridership points marked

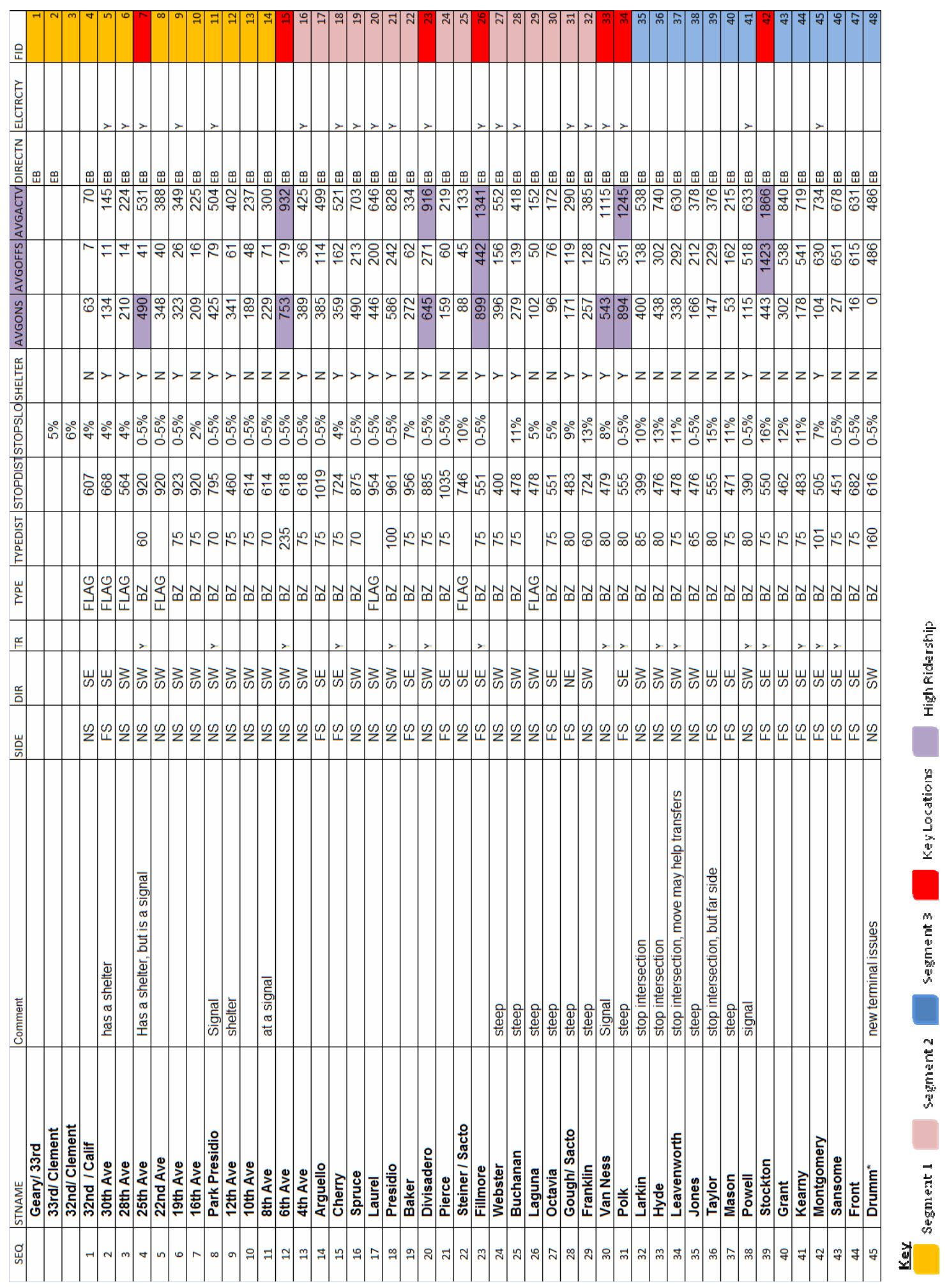


Figure 4-10. Key transfer points marked

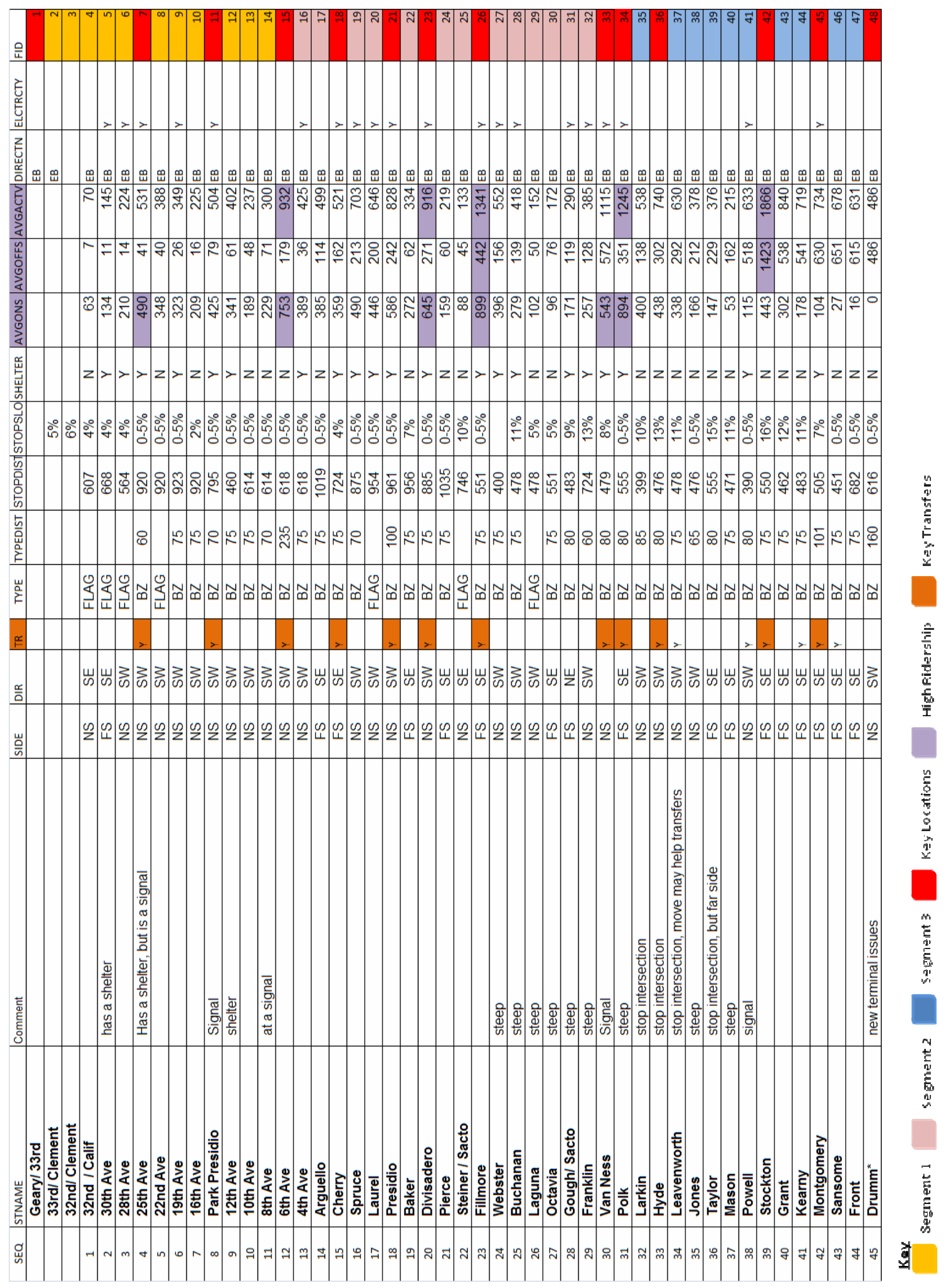


Figure 4-11. Alternative transfer points marked

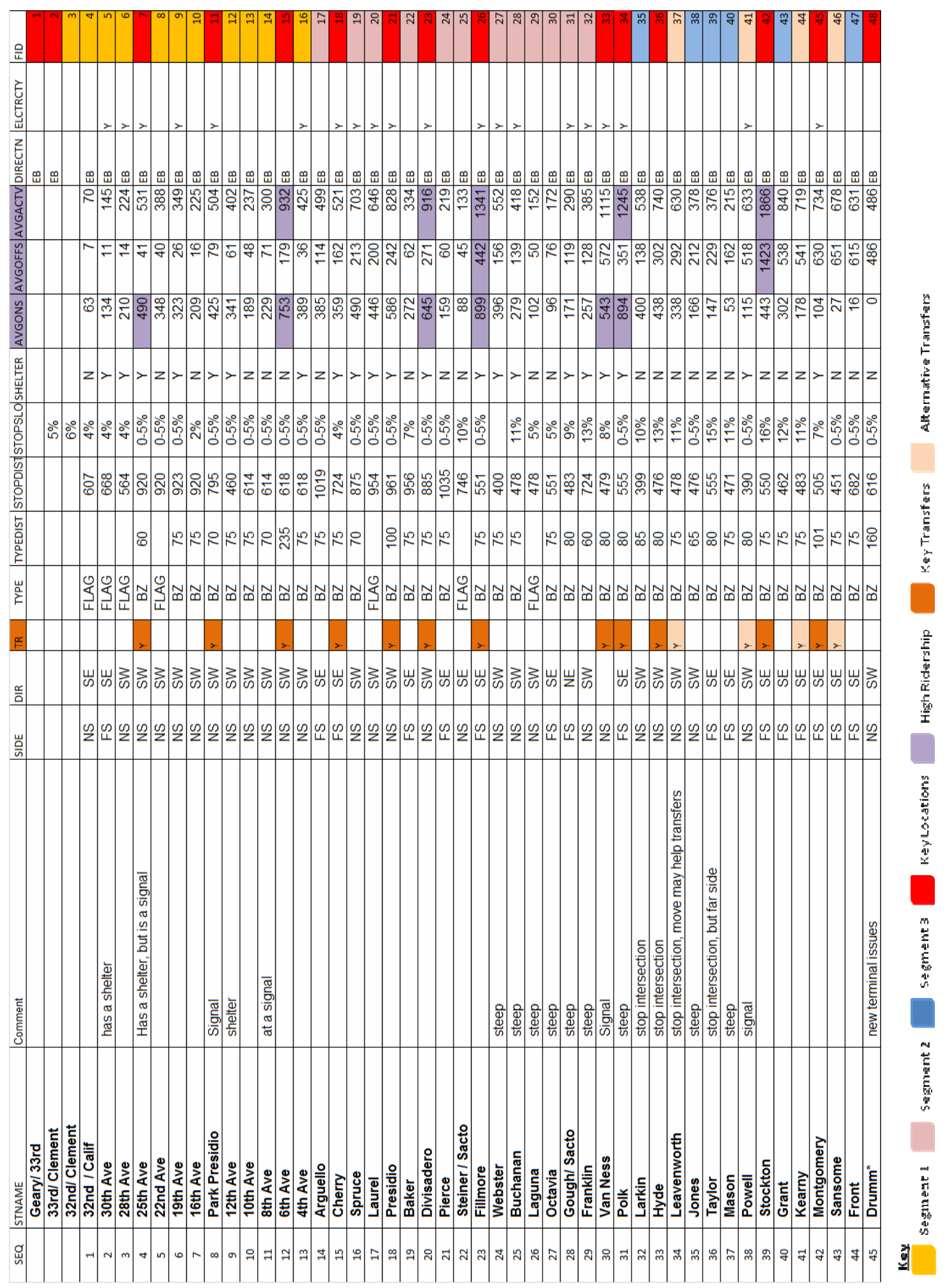


Figure 4-12. Existing shelters marked

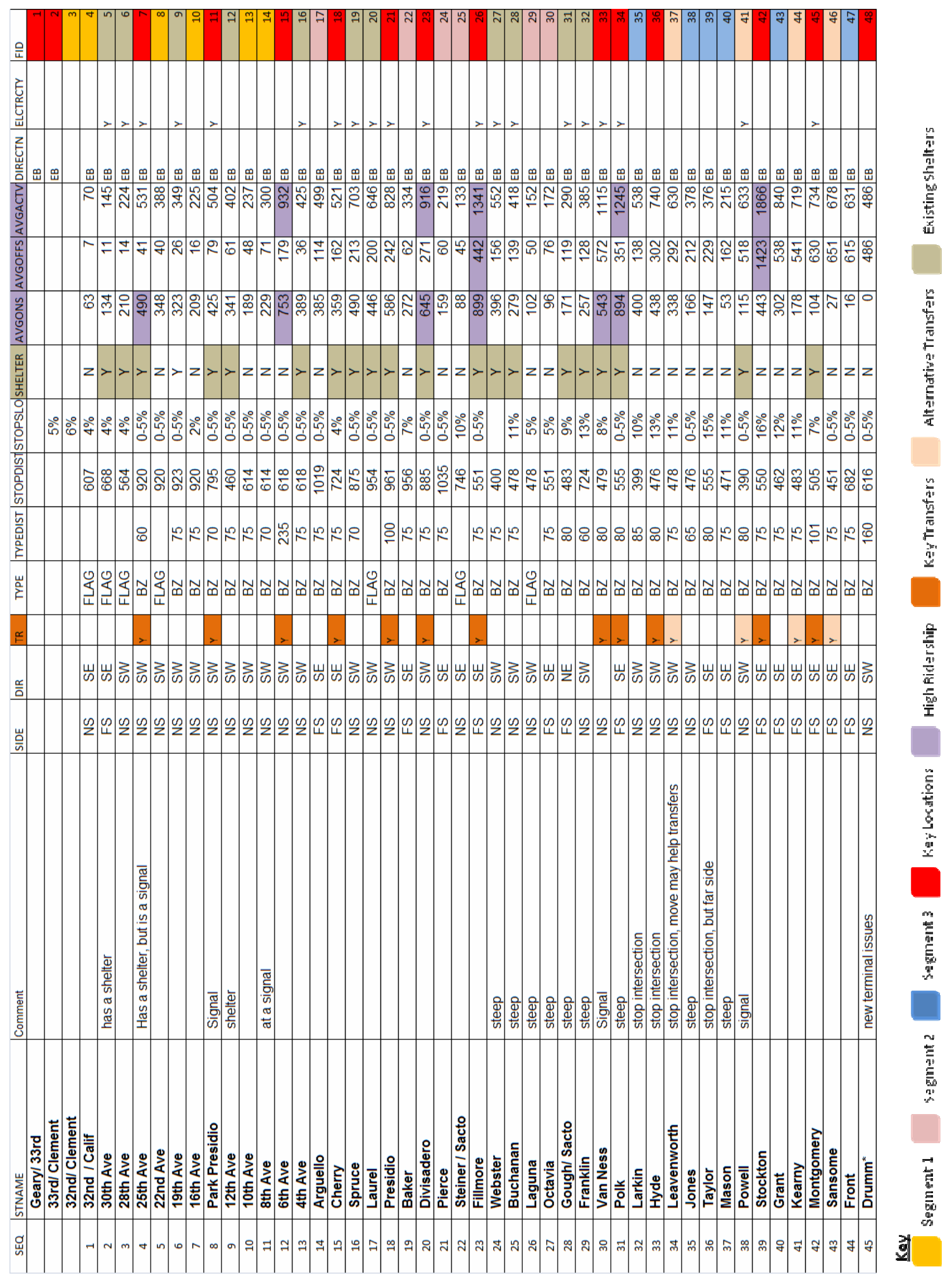


Figure 4-13. List of stops to keep

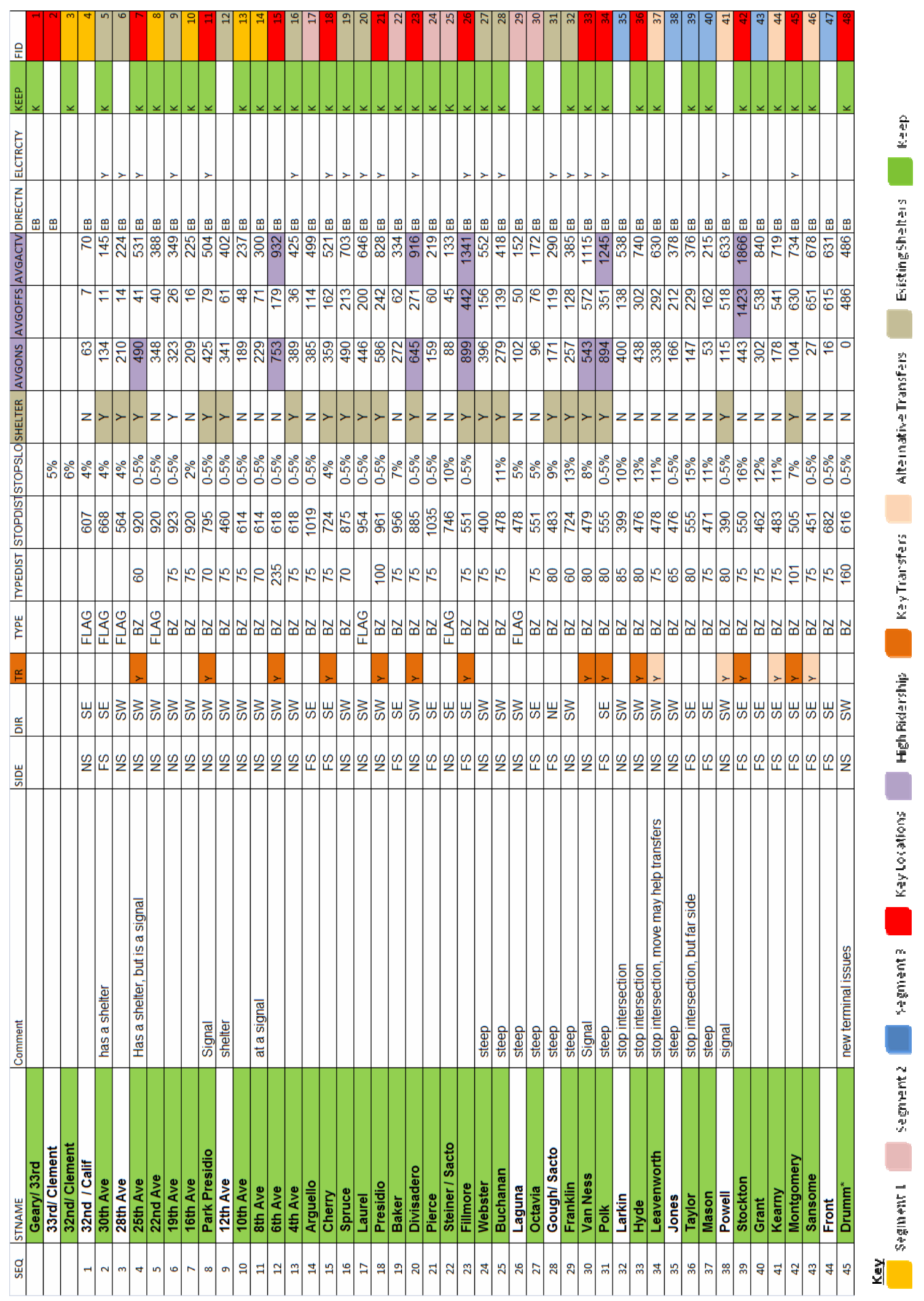


Figure 4-14. Final list of stops

\begin{tabular}{|c|c|c|c|c|c|c|c|c|c|c|c|c|c|c|c|c|c|}
\hline SEQ & STNAME & SIDE & DIR & $\overline{T R}$ & TYPE & TYPEDIST & STOPDIS & $\overline{\text { STOPSLO }}$ & HELTER & AVGONS & AVGOFFS & AVGACTV & DIRECTN & ELCTRCTY & KEEP & FID & ID \\
\hline & Geary/33rd & & & & & & & & & & & & EB & & $\kappa$ & & 1 \\
\hline & 32nd/ Clement & & & & & & & $6 \%$ & & & & & & & k & 3 & 2 \\
\hline 2 & 30th Ave & FS & SE & & FLAG & & 668 & $4 \%$ & $Y$ & 134 & 11 & 145 & EB & $Y$ & k & 5 & 3 \\
\hline 4 & 25th Ave & NS & SW & y & $B Z$ & 60 & 920 & $0-5 \%$ & $\mathrm{Y}$ & 490 & 41 & 531 & EB & Y & k & 7 & 4 \\
\hline 5 & 22nd Ave & NS & SW & & FLAG & & 920 & $0-5 \%$ & $\mathrm{~N}$ & 348 & 40 & 388 & EB & & k & 8 & 5 \\
\hline 6 & 19th Ave & NS & SW & & BZ & 75 & 923 & $0-5 \%$ & $\mathrm{Y}$ & 323 & 26 & 349 & EB & $Y$ & k & 9 & 6 \\
\hline 7 & 16th Ave & NS & SW & & $\mathrm{BZ}$ & 75 & 920 & $2 \%$ & $\mathrm{~N}$ & 209 & 16 & 225 & EB & & k & 10 & 7 \\
\hline 8 & Park Presidio & NS & SW & Y & BZ & 70 & 795 & $0-5 \%$ & $Y$ & 425 & 79 & 504 & EB & $y$ & k & 11 & 8 \\
\hline 10 & 10th Ave & NS & SW & & $\mathrm{BZ}$ & 75 & 614 & $0-5 \%$ & $\mathrm{~N}$ & 189 & 48 & 237 & EB & & k & 13 & 9 \\
\hline 11 & 8th Ave & NS & SW & & BZ & 70 & 614 & $0-5 \%$ & $\mathrm{~N}$ & 229 & 71 & 300 & EB & & k & 14 & 10 \\
\hline 12 & 6th Ave & NS & SW & $y$ & BZ & 235 & 618 & $0-5 \%$ & $\mathrm{~N}$ & 753 & 179 & 932 & EB & & k & 15 & 11 \\
\hline 13 & 4th Ave & NS & SW & & BZ & 75 & 618 & $0-5 \%$ & $Y$ & 389 & 36 & 425 & EB & $y$ & k & 16 & 12 \\
\hline 14 & Arguello & FS & SE & & BZ & 75 & 1019 & $0-5 \%$ & $\mathrm{~N}$ & 385 & 114 & 499 & $E B$ & & $\mathrm{k}$ & 17 & 13 \\
\hline 15 & Cherry & FS & SE & $y$ & BZ & 75 & 724 & $4 \%$ & $Y$ & 359 & 162 & 521 & EB & $Y$ & k & 18 & 14 \\
\hline 16 & Spruce & NS & SW & & BZ & 70 & 875 & $0-5 \%$ & $Y$ & 490 & 213 & 703 & EB & $y$ & $\kappa$ & 19 & 15 \\
\hline 17 & Laurel & NS & SW & & FLAG & & 954 & $0-5 \%$ & $\mathrm{Y}$ & 446 & 200 & 646 & $E B$ & Y & k & 20 & 16 \\
\hline 18 & Presidio & NS & SW & Y & BZ & 100 & 961 & $0-5 \%$ & $\mathrm{Y}$ & 586 & 242 & 828 & EB & $Y$ & $\mathrm{k}$ & 21 & 17 \\
\hline 19 & Baker & FS & SE & & BZ & 75 & 956 & $7 \%$ & $\mathrm{~N}$ & 272 & 62 & 334 & EB & & k & 22 & 18 \\
\hline 20 & Divisadero & NS & SW & Y & $\mathrm{BZ}$ & 75 & 885 & $0-5 \%$ & $\mathrm{Y}$ & 645 & 271 & 916 & EB & $Y$ & k & 23 & 19 \\
\hline 21 & Pierce & FS & SE & & BZ & 75 & 1035 & $0-5 \%$ & $\mathrm{~N}$ & 159 & 60 & 219 & $E B$ & & k & 24 & 20 \\
\hline 22 & Steiner / Sacto & NS & SE & & FLAG & & 746 & $10 \%$ & $\mathrm{~N}$ & 88 & 45 & 133 & EB & & $\mathrm{K}$ & 25 & 21 \\
\hline 23 & Fillmore & FS & SE & $Y$ & BZ & 75 & 551 & $0-5 \%$ & $Y$ & 899 & 442 & 1341 & EB & $Y$ & $\mathrm{k}$ & 26 & 22 \\
\hline 24 & Webster & NS & SW & & BZ & 75 & 400 & & $\mathrm{Y}$ & 396 & 156 & 552 & $E B$ & $Y$ & k & 27 & 23 \\
\hline 25 & Buchanan & NS & SW & & BZ & 75 & 478 & $11 \%$ & $Y$ & 279 & 139 & 418 & EB & $Y$ & k & 28 & 24 \\
\hline 27 & Octavia & FS & SE & & $B Z$ & 75 & 551 & $5 \%$ & $\mathrm{~N}$ & 96 & 76 & 172 & EB & & $\kappa$ & 30 & 25 \\
\hline 29 & Franklin & NS & SW & & BZ & 60 & 724 & $13 \%$ & $\mathrm{Y}$ & 257 & 128 & 385 & EB & $Y$ & $\kappa$ & 32 & 26 \\
\hline 30 & Van Ness & NS & & Y & BZ & 80 & 479 & $8 \%$ & $\mathrm{Y}$ & 543 & 572 & 1115 & $E B$ & $Y$ & k & 33 & 27 \\
\hline 31 & Polk & FS & SE & $\frac{Y}{y}$ & BZ & 80 & 555 & $0-5 \%$ & $Y$ & 894 & 351 & 1245 & $E B$ & Y & k & 34 & 28 \\
\hline 33 & Hyde & NS & SW & $\frac{y}{y}$ & BZ & 80 & 476 & $13 \%$ & $\mathrm{~N}$ & 438 & 302 & 740 & EB & & K & 36 & 29 \\
\hline 34 & Leavenworth & NS & SW & Y & BZ & 75 & 478 & $11 \%$ & $\mathrm{~N}$ & 338 & 292 & 630 & EB & & $k$ & 37 & 30 \\
\hline 36 & Taylor & FS & SE & & BZ & 80 & 555 & $15 \%$ & $\mathrm{~N}$ & 147 & 229 & 376 & EB & & $k$ & 39 & 31 \\
\hline 37 & Mason & FS & SE & & BZ & 75 & 471 & $11 \%$ & $\mathrm{~N}$ & 53 & 162 & 215 & EB & & k & 40 & 32 \\
\hline 39 & Stockton & FS & SE & $y$ & BZ & 75 & 550 & $16 \%$ & $\mathrm{~N}$ & 443 & 1423 & 1866 & EB & & k & 42 & 33 \\
\hline 40 & Grant & FS & SE & & BZ & 75 & 462 & $12 \%$ & $\mathrm{~N}$ & 302 & 538 & 840 & EB & & k & 43 & 34 \\
\hline 41 & Kearny & FS & SE & Y & BZ & 75 & 483 & $11 \%$ & $\mathrm{~N}$ & 178 & 541 & 719 & EB & & k & 44 & 35 \\
\hline 42 & Montgomery & FS & SE & $Y$ & BZ & 101 & 505 & $7 \%$ & $Y$ & 104 & 630 & 734 & EB & $Y$ & k & 45 & 36 \\
\hline 43 & Sansome & FS & SE & Y & BZ & 75 & 451 & $0-5 \%$ & $\mathrm{~N}$ & 27 & 651 & 678 & EB & & k & 46 & 37 \\
\hline 45 & Drumm $^{*}$ & NS & SW & & BZ & 160 & 616 & $0-5 \%$ & $\mathrm{~N}$ & 0 & 486 & 486 & EB & & K & 48 & 38 \\
\hline
\end{tabular}

$\underline{\underline{k} \text { ex }}$



Also, this project assumes that MTA wants to maintain the stops that are in existence rather than adding new stops. A concern is that removing and building a new stop may cause more confusion and cost more money than simply retaining a stop that may be slightly outside of the guidelines. If an agency is creating a route for the first time, it can adhere more closely to spacing standards. Trying to preserve some bus shelters may lead to slightly shorter or longer spacing distances than what is recommended in the guidelines. 
Figure 4-15. Route 1 California: 1/8 and 1/4 mile buffers

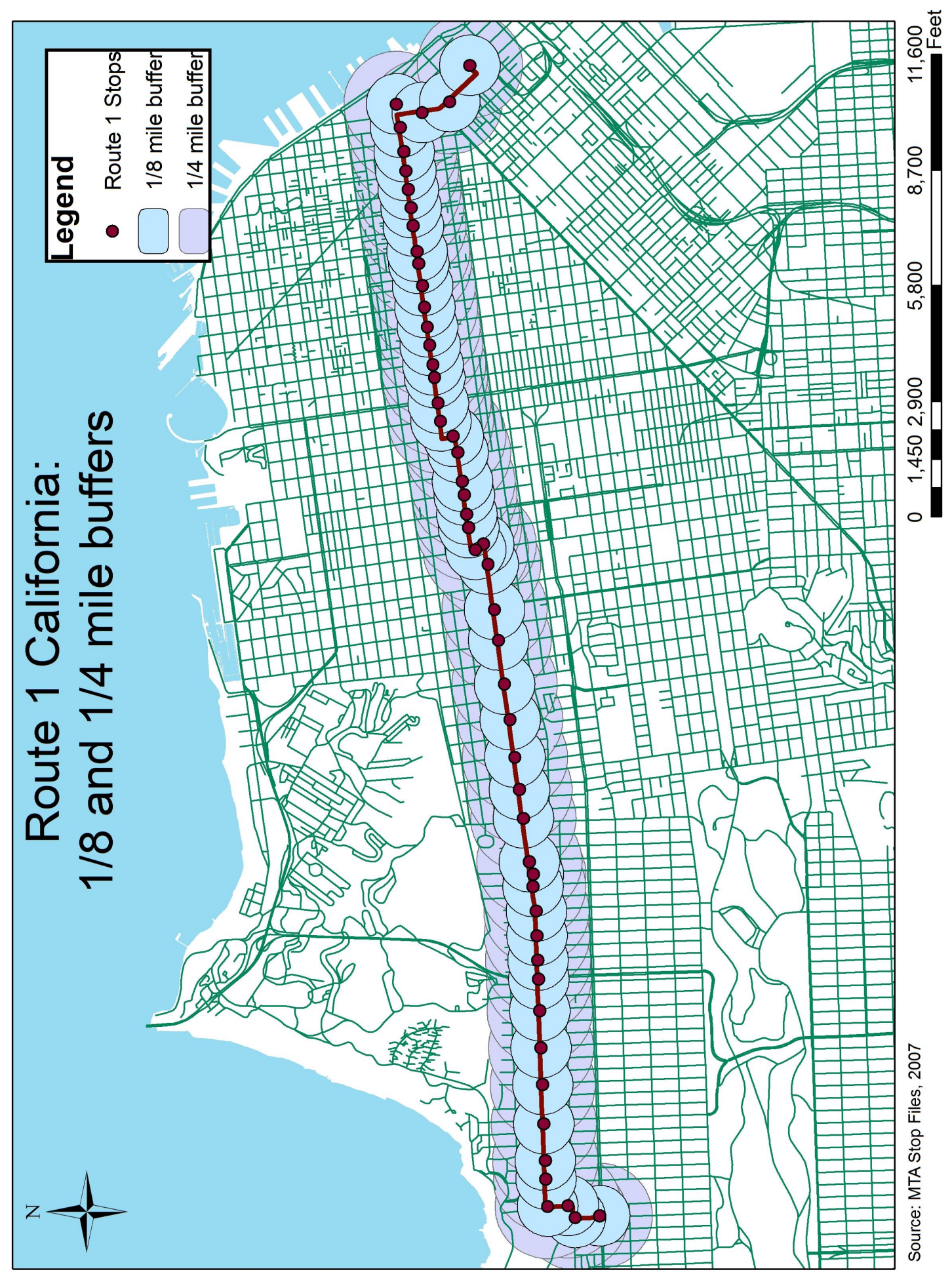


Figure 4-16. Modified Route 1 California: 1/8 and 1/4 mile buffers

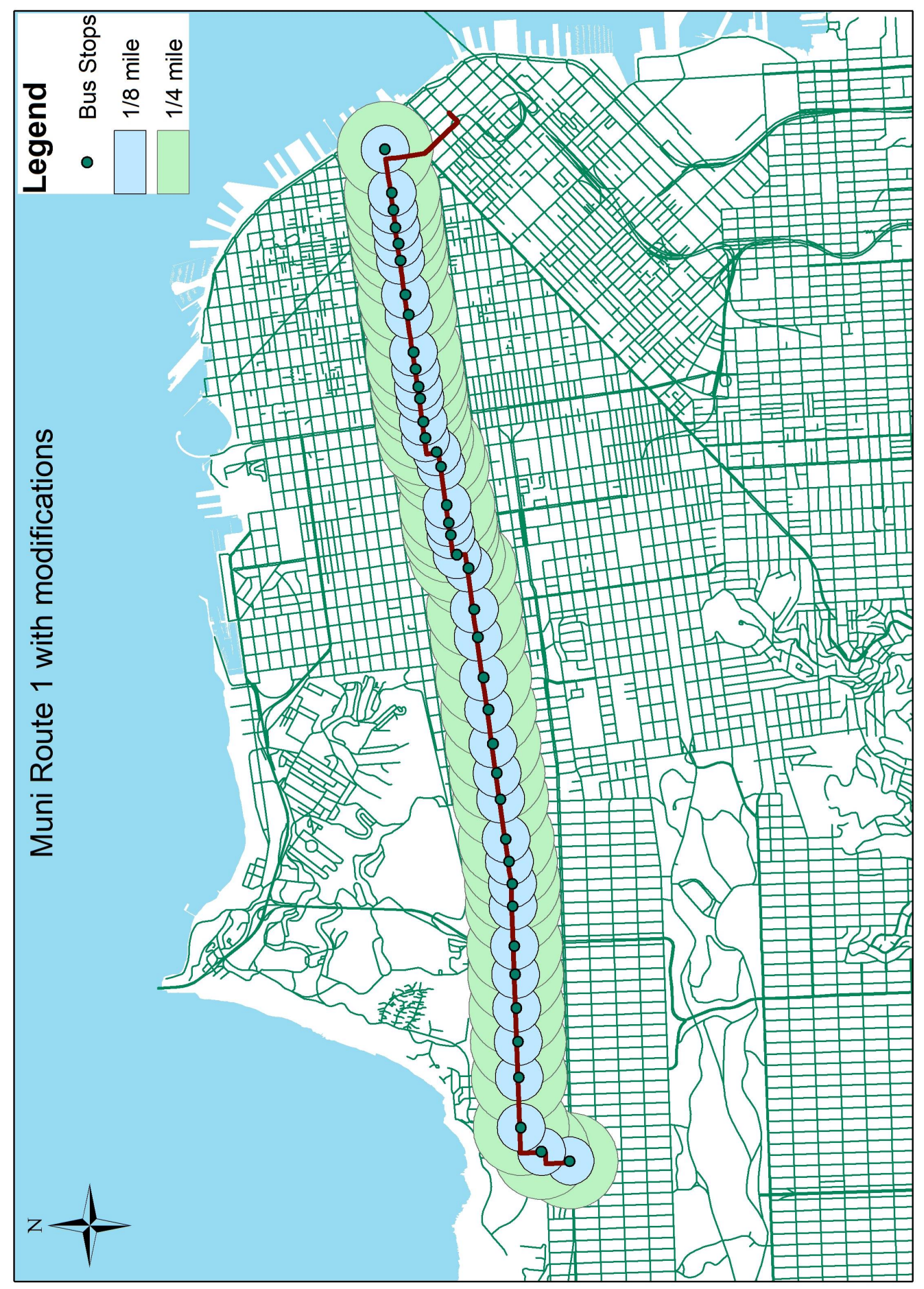




\section{Evaluation of new route proposal}

Originally, there were 48 stops along the route, taking into account recent route changes developed by the Transit Effectiveness Project (TEP). The stop consolidation exercise reduced this number to 38 , or 10 fewer bus stops. The route at present is approximately 40 minutes and 6 miles long (from $33^{\text {rd }}$ and Geary to the new Drumm Terminal). This equates to an overall average speed of $9 \mathrm{mph}$. The evaluation of the impact of the route changes is based on values from the literature which gave estimates for time or cost savings.

Using dwell time estimates from the literature review, each eliminated stop could reduce total dwell time by 15 to 40 seconds. This equates to between 2.5 and 7 minutes per route or a 6 to $16 \%$ reduction in travel time (Table 4-1). These values also correspond to estimated travel time savings from EOT (2008) of between 6 and 18 percent. Based on values from Furth and Rahbee (2000), the deceleration, dwell, and acceleration at each stop takes 17 seconds (Appendix 3). This is a fairly low estimate, but would reduce travel time on a route by about 2.8 minutes.

\section{Table 4-1. Dwell time reduction estimates}

\begin{tabular}{|c|c|c|}
\hline $\begin{array}{c}\text { Dwell time } \\
\text { reduction per stop }\end{array}$ & Minute Reduction & $\begin{array}{c}\text { Percentage } \\
\text { Reduction }\end{array}$ \\
\hline 15 & 2.5 & $6 \%$ \\
\hline 40 & 6.7 & $17 \%$ \\
\hline
\end{tabular}


There are approximately 200 inbound services of Route 1 California every weekday. If this time reduction is applied to the entire route (Table 4-2) it saves between 8 and 23 hours of service over the day.

Table 4-2. Dwell time reduction estimates

\begin{tabular}{|l|c|c|c|}
\hline & Minutes & Hours & Hours saved \\
\hline Current Route & 8000 & 133.3 & \\
\hline $6 \%$ Reduction & 7500 & 125.0 & 8.3 \\
\hline $17 \%$ Reduction & 6660 & 111.0 & 22.3 \\
\hline
\end{tabular}

Furth and Rahbee (2000) gave estimates for operating costs and total societal costs. If operating costs are approximately $\$ 80$ per hour, then improvements to one direction of one route could save approximately $\$ 170,000$ to $\$ 464,533$. The societal cost value represents values of time for operating, riding, and walking. This total cost savings could be between $\$ 286,000$ and $\$ 766,480$. If similar reductions could be achieved across the 10 highest ridership routes, which have similar service frequencies, the agency could be worth between $\$ 3.4$ million and $\$ 9.2$ million.

Table 4-3. Estimated savings in operating and societal costs

\begin{tabular}{|c|c|c|c|c|}
\hline & \multicolumn{2}{|c|}{ Operating Cost } & \multicolumn{2}{|c|}{ Societal Cost } \\
\hline & Daily Savings & Yearly Savings & Daily Savings & Yearly Savings \\
\hline $6 \%$ Reduction & 667 & $\$ \quad 173,333$ & 1,100 & 286,000 \\
\hline 17\% Reductio & 1,787 & $\$ 464,533$ & 2,948 & 766,480 \\
\hline
\end{tabular}

Figure 4-17. Summary of cost estimation process 
DWELL TIME

REDUCTION
ROUTE TIME

REDUCTION
DAILY HOURS OF

SERVICE

REDUCTION
OPERATING

COST

REDUCTION

SOCIETAL COST

REDUCTION

Another method for estimating the time savings per route is using CTA bus speed increase estimates. CTA (2003) shows that an express route with 75 percent fewer stops, increased average travel speeds by 25 percent. Applying this same rate to the data for Route 1 (Table 4-4) shows that the average speed would theoretically increase by $0.63 \mathrm{mph}$, and save 8.7 hours of service each day. This value is close to the lower end estimate in Table 4-2.

Table 4-4. Average speed increase estimate

\begin{tabular}{|l|l|c|c|c|}
\hline & Speed & Minutes & Hours & Hours saved \\
\hline Current Route & $9 \mathrm{mph}$ & 8000 & 133.3 & \\
\hline Increase speed & $9.63 \mathrm{mph}$ & 7477 & 124.6 & 8.7 \\
\hline
\end{tabular}

The average speed increase over the route shown in Table 4-3 is 0.63 mph. This small average speed increase could also represent savings in fuel and oil consumption. For example, at very low speeds, for every $5 \mathrm{mph}$ speed increase, 100 fewer gallons of fuel are consumed per 1,000 miles (TTI, 1990).

Table 4-5 converts this to units for the $0.63 \mathrm{mph}$ estimated speed increase.

Table 4-5. Reduction in costs based on average speed increase

\begin{tabular}{|c|c|c|c|cr|}
\hline & Units & Daily & Yearly & \multicolumn{1}{|c|}{ Cost } \\
\hline Route & 6 miles & 1200 miles & 312000 miles & & \\
\hline Fuel & $12.6 \mathrm{gal} / 1000$ miles & 15 gallons & 3930 gallons & $\$, 048$ \\
\hline Oil & $0.63 q$ ts $/ 1000$ miles & 0.8 quarts & 195 quarts & $\$$ & 125 \\
\hline
\end{tabular}


Based on the literature review, there is an additional method for estimating specific costs for fuel and oil. Table 4-6 uses data from Raus (1981 in Vuchic 2007) on the gallons per mile fuel consumption versus bus stops per mile. Again, this proposal shows a savings of about $\$ 32,000$ for the year.

Table 4-6. Fuel consumption based on stops per mile

\begin{tabular}{|l|c|c|c|c|}
\hline & Stops per mile & Gallons/mile & Gallons/route & Gallons/day \\
\hline Existing & 8 & 0.4 & 2.4 & 480 \\
\hline Proposed & 6.3 & 0.3 & 1.8 & 360 \\
\hline Difference & & & 0.6 & 120 \\
\hline
\end{tabular}

\begin{tabular}{|l|c|c|c|}
\hline & Gas Price & Cost & Yearly Cost \\
\hline Existing & $\$ 1.03$ & $\$ 494$ & $\$ 128,544$ \\
\hline Proposed & $\$ 1.03$ & $\$ 371$ & $\$ 96,408$ \\
\hline Difference & & $\$ 124$ & $\$ 32,136$ \\
\hline
\end{tabular}

There is significant difference between the $\$ 4,000$ and $\$ 32,000$ estimate for fuel savings shown in Tables 4-4 and 4-5. However, both figures, when applied over the extent of the system will represent significant cost savings, especially considering the likely increase in gas prices. Combined with the passenger benefits of stop spacing makes this a valuable undertaking for the SFMTA. 


\section{CHAPTER 5: PUBLIC OUTREACH AND IMPLEMENTATION}

\section{$\underline{5.1 \text { Public Outreach }}$}

The public outreach effort should involve three major aspects: expressing to the community the costs and benefits of stop consolidation, explaining the stop consolidation process and asking the community for input on key stop locations.

Costs of implementation:

- Reduces access to stops/greater walking distances

- Changes to the stop locations may be confusing

Benefits of implementation:

- Buses can travel faster on more segments of the route/travel time is reduced/operating costs are reduced

- Savings could be spent on further treatments to increase bus speeds

- Savings could also be used to increase bus frequency which can increase reliability

Example of Stop Consolidation Process:

- Using steps from chapter 4, show how the stops are eliminated (not just arbitrary eliminations)

- Show time and savings expectations

Input on Stop Locations:

After breaking a route into segments: 
- Have community members give input on which 2 or 3 stops are the most important in each segment.

- Ask which transfer points are most often used

- Show that this information will be used to place the additional stops

- Ask community about additional issues associated with stop reduction along this particular route

\section{$\underline{5.2}$ Implementation}

Before applying stop consolidation to all routes on the system, one route should serve as a test run and an example. Consolidations for a route must consider revised scheduling and as well as elimination of stops themselves.

\section{Revised schedules}

The literature showed that appropriate schedules must be developed to allow for maximum benefit from stop consolidation. Specific considerations are as follows:

- Locations where bus priority measures are planned, such as bus bulbs

- Locations for bus priority signalization

- Locations that currently cause significant congestion which interferes with run time 
Considering these factors, estimate of actual travel time along the route, using estimates from the literature review or estimates based on dwell time data from APCs.

\section{Elimination of bus shelters}

Because MTA does not own bus shelters, all changes to stop locations must be checked with plans for future bus shelter placements. Any bus shelters that will be eliminated must be accounted for so that MTA does not fall below the minimum required number of bus shelters according its contract.

\section{Notification of stop changes}

Each stop location should provide notification to customers for a minimum of two weeks prior to the closure of the bus stop. Similar notifications should be considered throughout the surrounding neighborhoods, along with suggestions of the next closest bus stop. Notifications should also include information on schedule changes for the route.

\section{Marking stop removal}

Not all stops will be able to be moved immediately, but stops should be clearly marked as out-of-service stops to minimize confusion for the public. Work orders to remove route numbers for bus stop signs should be organized so they are put into effect on the same day. 


\section{Evaluation of test route}

Once the bus stops have been eliminated, the route should be monitored to see reductions to the overall route time as well as specific segments. This

information should be compared to eliminations in each segment as well as ridership characteristics and bus priority measures to see the overall effectiveness of the program and which factors help or hinder the process. 


\section{CHAPTER 6: CONCLUSION}

The purpose of this report was to analyze the elements of a bus stop consolidation program for the San Francisco Municipal Transportation Agency (SFMTA). This program is one element of the implementation of the Transit Effectiveness Project (TEP). SFMTA has worked to improve its existing guidelines and use the guidelines to create route proposals for stop elimination.

This research shows that increasing stop spacing distances increases walking distances, but in places with high transit and stop density, most access distances will not be beyond a five to ten minute walk. At the same time, fewer stops will concentrate passengers at the remaining stops along the route, which increases predictability, allows for a more accurate schedule, and creates a more reliable service. Concentrating passengers can also reduce the dwell time per passenger per stop, which leads to an overall reduction in route travel time.

Reducing travel time reduces operating expenses which in turn allows the agency to provide more stop amenities, and continue to reduce dwell time. Reduced operating expenses may also translate into more frequent service, which can reduce bus bunching, also leading to a more accurate schedule and a more reliable service. Ultimately, a more reliable service means passengers will spend less time waiting at bus stops.

There are many cities throughout the country and world that have institute stop consolidation programs and created stop spacing guidelines. In general, 
European cities recommend 3 to 4 stops per mile, or approximately every 1300 feet. American guidelines recommend stops between approximately 800 to 1300 feet. The proposed stop spacing guidelines for San Francisco range from 900 to 1400 feet. This is on the high end of American standards, but low compared to European standards. Because European systems have greater transit mode share than the US, moving towards European stop spacing standards is justified. This report also contains many considerations for specific siting of stops. These factors can be used to different degrees for any city which is considering a stop consolidation program.

The methodology for creating stop elimination proposals ranked the factors considered most important for bus routes. The factors are, stops with highest ridership, transfer points, alternative transfer points, and stops with existing bus shelters or infrastructure. Public input can also help to determine which bus stops are key locations. In public outreach, agencies should pay particular attention to locating stops which serve transit dependent populations.

Finally, this methodology was used to propose stop consolidation for one bus route in San Francisco: Route 1 California Inbound. The same methodology was also used for the outbound route, and the inbound and outbound route were checked for stop correspondence. The route was then evaluated based on information from the literature review. The general findings are that walking distances increase, but still remain within $1 / 4$ of a mile for most of the effected population. The yearly savings per route are estimated to be a minimum of $\$ 340,000$ per route. Before implementing the proposals, bus schedules must be 
revised to get maximum benefit out of the program. Customers need notification in order to facilitate transition from the existing route to the new route.

Planners should take this methodology and determine criteria that are important in their city to create similar proposals for their bus routes. Hopefully, this research shows why increasing stop spacing distances is beneficial for both the agency and the customers. Explaining to the public the benefits of the program, providing an objective method for determining which stops remain in place, showing examples of successful standards in Europe, and allowing people to participate in the program should create a successful project.

Because of data limitations, this paper does not show projected reductions in dwell time based on the number of customers projected to use remaining bus stops. This value could help to create a more accurate schedule for initial attempts at stop reduction. Also, this research does not attempt to quantify reductions in wait time or place values on increased reliability. This paper attempts to quantify the costs an cost savings associated with stop consolidation, but further research on the maintenance aspects of cost savings would further inform this study. 


\section{REFERENCES}

AC Transit. (1989). Bus Stop Policy. Retrieved from

http://www.actransit.org/pdf/board_policies/policies/board_policy_41.pdf?PHPSES $\mathrm{SID}=$ ea1551e056d7713ab34838ed2b92dc94.

American Community Survey (2008). Table C08301 Means of Transportation to Work.

Bowman, L., \& Turnquist, M. (1981). Service frequency, schedule reliability and passenger wait times at transit stops. Transportation Research Part A, 15(6): 465471.

Chaves, E., Garcia, E., and S. Gilmore. (2006). Consensus Building in Transportation Planning Practice: Case Evaluation of Process and Outcomes. Transportation Research Record: Planning and Analysis, no. 1981.

Chicago Transit Authority. (2001). Chicago Transit Authority Service Standards. Chicago, IL.

Chicago Transit Authority (2003). Neighborhood Express Bus Routes. Retrieved from http://www.fta.dot.gov/assistance/technology/research_4324.html.

Curitiba, Brazil: BRT Case Study. (2003). Retrieved from http://nexus.umn.edu/Courses/ce5212/Case3/Curitiba.pdf

Darnell \& Associates. (2006). Bus Stop Design Guidelines. Prepared for Omnitrans. San Diego, CA.

El-Geneidy, A., Kimpel, T., and Stratham, J. (2005). Empirical Analysis of the Effects of Bus Stop Consolidation on Passenger Activity and Transit Operations. Retrieved from http://www.upa.pdx.edu/CUS/publications/projectreports.html.

Federal Highway Administration. (2009). 10 Simple Steps to Reducing Climate Change. Retrieved from http://www.fhwa.dot.gov/hep/climate/tensteps.htm.

Federal Transit Administration. (2006). Stops, Spacing, Locations and Design. Retrieved from http://www.fta.dot.gov/assistance/technology/research_4361.html.

Furth, P., \& Rahbee, A. 2000. Optimal bus stop spacing through dynamic programming and geographic modeling. Transportation Research Record, 1731: 15-22. 
Hopes, C., Kramer, J. and K. Williams. (2006). Public Involvement Practices and Perspectives of Florida's Metropolitan Planning Organizations. Transportation Research Record: Planning and Analysis, no. 1981.

Intercity Transit. (n.d.). Bus Stop Specification Guidelines. Olympia, WA.

Kittleson and Associates. (2006). Transit Speed and Delay Study. Prepared for Florida Department of Transportation. Portland, OR.

Liu, R., and Sinha, S. (2007) Modelling Urban Bus Service and Passenger Reliability. Conference Proceedings from The Third International Symposium on Transportation Network Reliability. The Hague, Netherlands.

Massachusetts Executive Office of Transportation. (2008). Route 39 Enhancement Plan. Retrieve from http://www.eot.state.ma.us/downloads/ Route_39_Presentation.pdf

McAndrews, C., Florez, J., and E. Deakin. (2006). Views of the Street: Using Community Surveys and Focus Groups to Inform Context-Sensitive Design. Transportation Research Record: Planning and Analysis, no. 1981.

Mohring, H., Schroeter, J., and Wiboonchutikula, P. (1987). The value of waiting time, travel time, and a seat on a bus. Rand Journal of Economics, 18(1): 40-56. Municipality of Metropolitan Seattle. (1991). Metro Transportation Facility Design Guidelines. Seattle, WA.

Municipality of Metropolitan Seattle (1991). Metro Transportation Planning Facility Design Guidelines.Seattle, WA.

Murray, A., \& Wu, X. (2003). Accessibility tradeoffs in public transit planning. Journal of Geographical Systems, 5(1): 93-107.

Oort, N. and Nes. R. (2003). Service Regularity Analysis for Urban Transit Network Design, Paper presented at TRB Annual Meeting, January, Washington $D C$.

Pedestrian and Bicycle Information Center. (2009). Improving Transit Stop/Station Access. Retrieved from http://www.walkinginfo.org/transit/ access.cfm

San Francisco Municipal Railway. (1979). Short Range Transit Plan (1979-1984). San Francisco, CA.

San Francisco Municipal Transportation Agency. (2009a). Presentation on Stop Spacing. San Francisco, CA. 
San Francisco Municipal Transportation Agency. (2009b). Transit Effectiveness Project. Retrieved from http://www.sfmta.com/cms/mtep/tepover.htm.

Texas Transportation Institute. (1990). Technical Memorandum for National Cooperative Highway Research Program Project 7-12. College Station, TX.

Texas Transportation Institute. (1996). Guidelines for the Location and Design of Bus Stops. TCRP Report 19, Transit Cooperative Research Program, Transportation Research Board, National Research Council.

Transport for London. (2006). Accessible Bus Stop Design Guidance. London, UK.

Tri-County Metropolitan Transportation District of Oregon. (2002). Bus Stop Guidelines 2002. Portland, OR.

Tri-County Metropolitan Transportation District of Oregon. (1989). TriMet Service Standards. Portland, OR.

Turnquist, M. (1981). Strategies for improving reliability of bus transit service. Transportation Research Record 818: 7-13.

United States Department of Energy (2009). Driving more efficiently. Retrieved from http://www.fueleconomy.gov/feg/driveHabits.shtml

United States Department of Justice. (2005). A guide to Disability Rights Law. Retrieved from http://www.ada.gov/cguide.htm.

Waterson, B.J., Rajbhandari, B., and Hounsell, N.B. (2003). Simulating the Impacts of Strong Bus Priority Measures. Journal of Transportation Engineering, 129(6), pp. 642-647.

Vuchic, V. (2007). Vehicle Motion and Performance. In Urban Transit: Systems and Technology. Hoboken, NJ.

Washington Area Metropolitan Transit Authority. (2009). Metrobus Veirs Mill Line Study. Retrieved from http://www.metrobus-q2.com/index.htm. 
APPENDICES

Appendix 1: Route 1 California Outbound - Stops with standard deviations greater than one

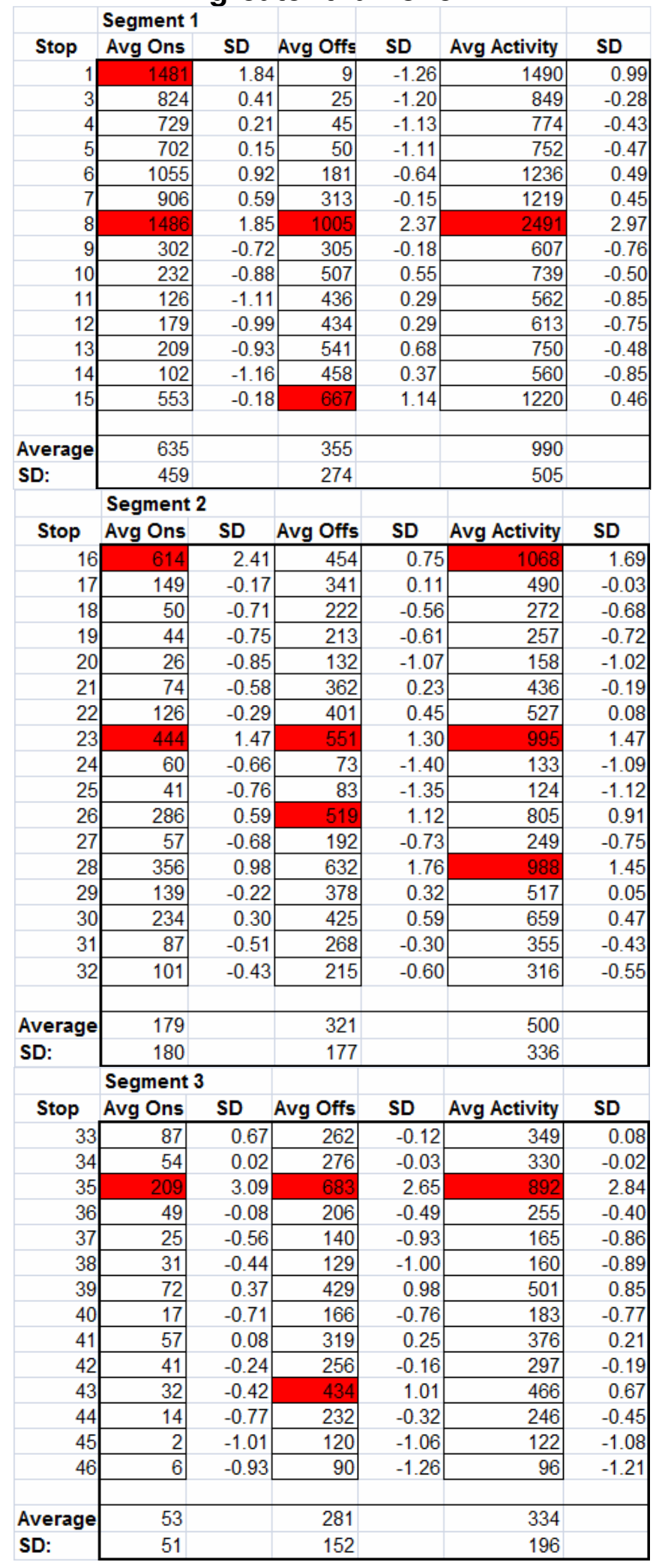




\section{Appendix 2: Route 1 California Outbound - List of Stops to Keep}

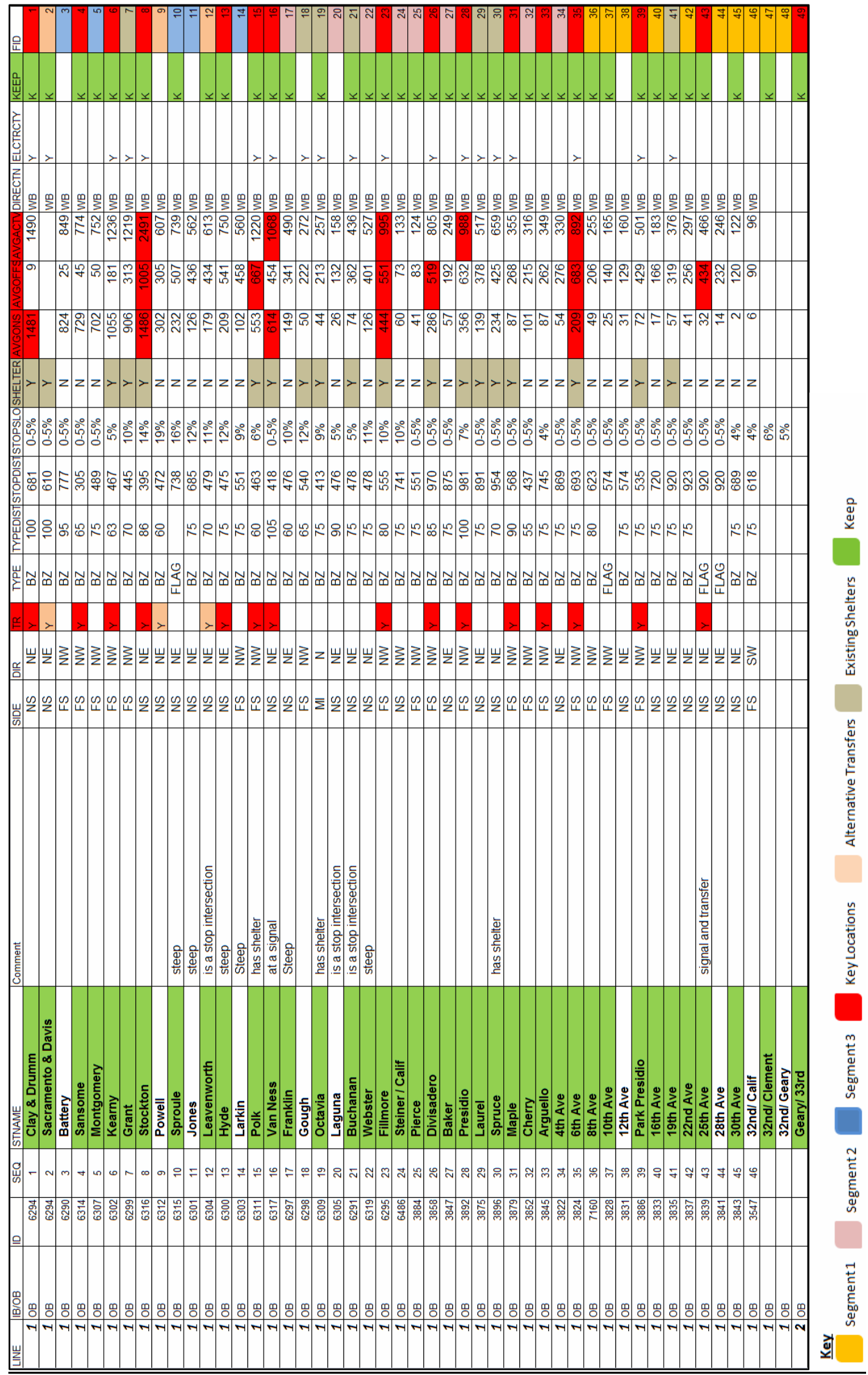

